Portland State University

PDXScholar

\title{
A Case Study of Twelve Japanese ESL Students' Use of Interaction Modifications
}

Darin Dooley

Portland State University

Follow this and additional works at: https://pdxscholar.library.pdx.edu/open_access_etds

Part of the Bilingual, Multilingual, and Multicultural Education Commons, Educational Assessment, Evaluation, and Research Commons, and the Japanese Studies Commons Let us know how access to this document benefits you.

\section{Recommended Citation}

Dooley, Darin, "A Case Study of Twelve Japanese ESL Students' Use of Interaction Modifications" (1997). Dissertations and Theses. Paper 5576.

https://doi.org/10.15760/etd.7362

This Thesis is brought to you for free and open access. It has been accepted for inclusion in Dissertations and Theses by an authorized administrator of PDXScholar. Please contact us if we can make this document more accessible: pdxscholar@pdx.edu. 


\section{THESIS APPROVAL}

The abstract and thesis of Darin Dooley for the Master of Arts in TESOL were presented March 6, 1997, and accepted by the thesis committee and the department.

COMMITTEE APPROVALS:

Marjorie's. Terdal, Chair

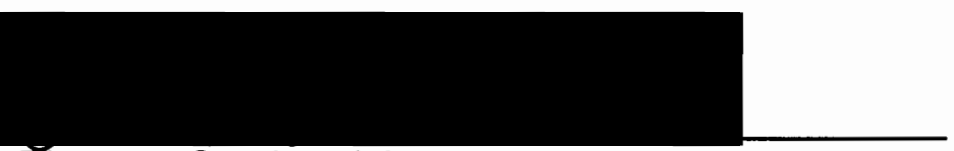

Thomas G. Dieterich

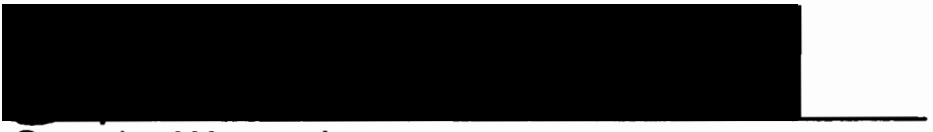

Suwako Watanabe

Representative of the Office of Graduate Studies

DEPARTMENT APPROVAL:

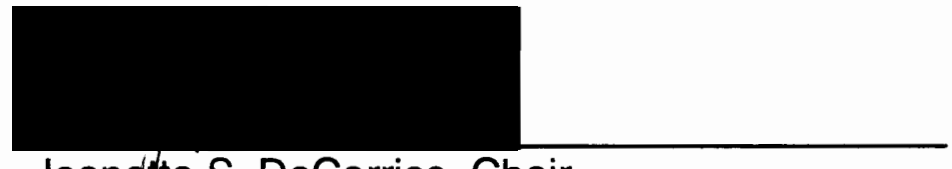

Jeanefte S. DeCarrico, Chair

Department of Applied Linguistics

ACCEPTED FOR PORTLAND STATE UNIVERSITY BY THE LIBRARY

by

on

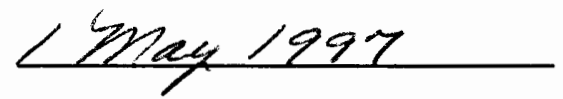


An abstract of the thesis of Darin Dooley for the Master of Arts in TESOL presented March 6, 1997.

Title: A Case Study of Twelve Japanese ESL Students' Use of Interaction Modifications.

This case study examines Japanese ESL students' use of interaction modifications in a content based course. Twelve female subjects were observed and recorded during a nine week period. Their use of interaction modifications (clarification requests, confirmation checks, and comprehension checks) and responses to interaction modifications (single word, full or partial repetition, or reformulation), during teacher-fronted and small group situations, were recorded and coded using the COLT observation instrument.

The study found that the subjects used clarification requests over four times more often in small group or pair-work situations than in teacherfronted classes. Also, the subjects used confirmation checks over five times more often in small group and pair-work situations than in teacher-fronted classes. The subjects did not use comprehension checks in either teacherfronted or small group situations.

The results from the data collection were correlated with increases in Michigan Test and CELT test scores using the Spearman and Pearson correlation statistics. The results indicated that there was a significant 
positive correlation (Spearman correlation coefficient $=0.758568, p<0.004$ ) between use of interaction modifications and increase in CELT test scores, whereas there was no significant correlation between use of interaction modifications and increase in Michigan Test scores. Furthermore, no correlation was found between type of response to interaction modifications and increase in either Michigan Test or CELT test scores. Discussion of these findings centers on the roles that classroom style and Japanese socio-cultural values play in Japanese ESL students' use of interaction modifications and length of response to clarification requests and confirmation checks. 
A CASE STUDY OF TWELVE JAPANESE ESL STUDENTS' USE OF INTERACTION MODIFICATIONS

$$
\text { by }
$$

Darin Dooley

\section{A thesis submitted in partial fulfillment of the requirements for the degree of}

\section{MASTER OF ARTS}

in

TESOL

Portland State University

1997 


\section{ACKNOWLEDGMENTS}

I would like to thank my thesis advisor Marjorie Terdal for her support and assistance throughout this research. She has made numerous suggestions and criticisms which have improved this study. I am very grateful for the time she has spent, and for the encouragement, direction and advice she has given. I would also like to thank the other committee members, Prof. Dieterich and Prof. Watanabe, for their valuable comments and suggestions. I would especially like to thank Prof. Watanabe for her help with my research of Japanese culture. She has provided many interesting and enlightening explanations that have helped me to better understand Japanese socio-cultural values and their effect on interaction.

I would also like to thank the subjects and instructor who so graciously allowed me to observe their class, and without whose cooperation this thesis would not have been possible.

I owe a special debt to my family for all their support and encouragement throughout my course work and thesis project.

Finally, I would like to thank my lovely wife Yuki, who has supported me throughout my time at PSU and made many sacrifices so that I might pursue my dream. 


\section{TABLE OF CONTENTS}

ACKNOWLEDGMENTS

LIST OF TABLES viii

LIST OF FIGURES ix

\section{CHAPTER}

I INTRODUCTION

Theoretical Foundation ........................................................ 2

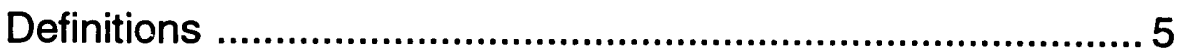

Research Questions ......................................................... 7

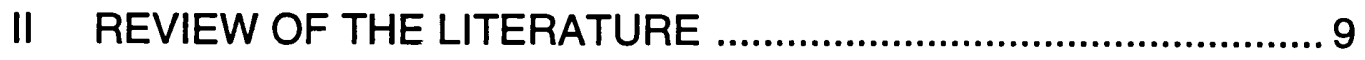

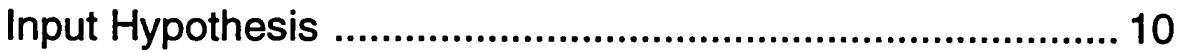

Interaction Hypothesis ....................................................... 11

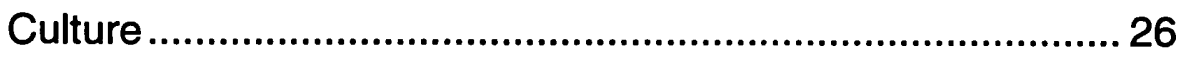

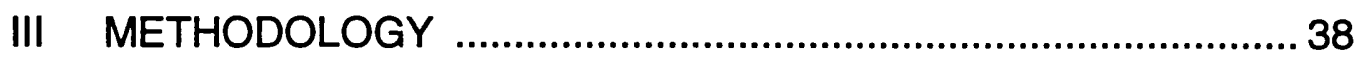

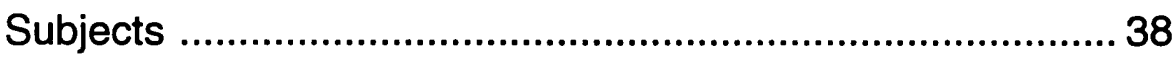

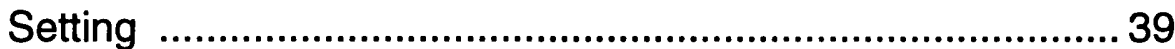

Instruments and Materials ................................................ 40

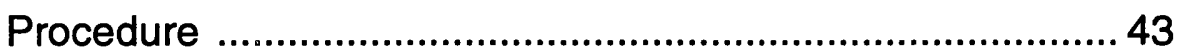

Analysis of Data .............................................................. 45

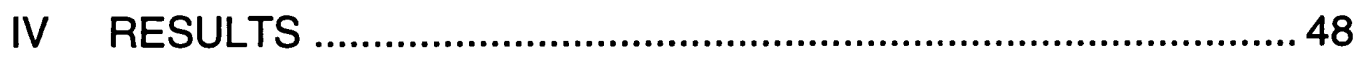

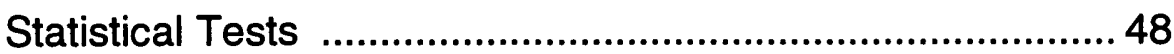


Subject Use of Interaction Modifications .............................. 49

Subject Response to Interaction Modifications .................... 54

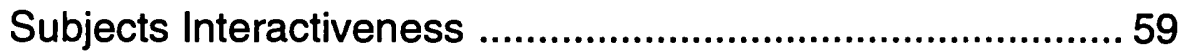

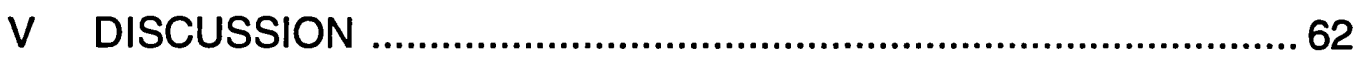

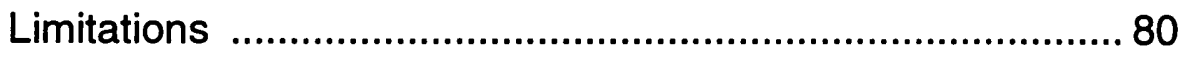

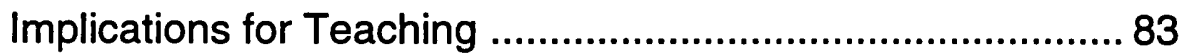

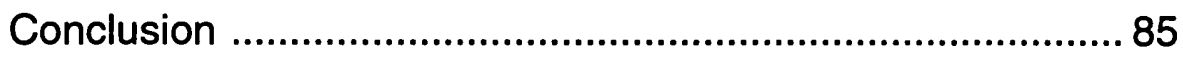

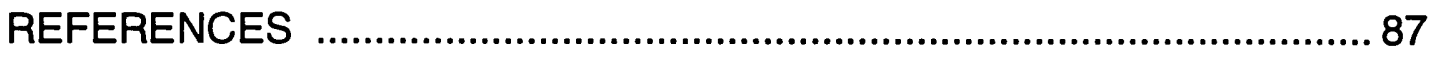

APPENDICES

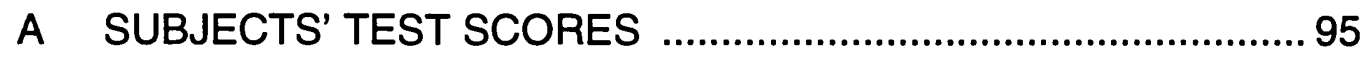

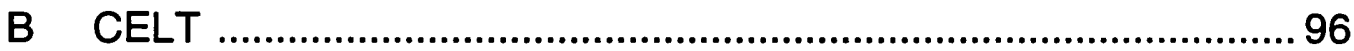

C SAMPLE CORPUS AND CODING ..........................................98 


\section{LIST OF TABLES}

\section{TABLE}

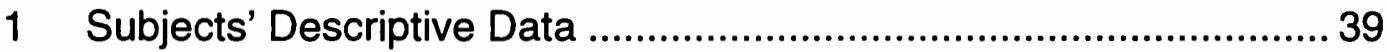

2 Subjects' Use of Interaction Modifications in Teacher-Fronted Classes

3 Subjects' Use of Interaction Modifications in Small Group/Pair-Work Situations

4 Correlation of Subjects' Use of Interaction Modifications and Increase in Test Scores.

5 Weighted Interaction Modifications - Increase in Test Scores Correlation

6 Revised Weighted Interaction Modifications - Increase in Test Score Correlation

7 Subjects' Responses to Clarification Requests................................55

8 Subjects' Responses to Confirmation Checks ................................56

9 Responses to Interaction Modifications - Increase in Test Score Correlation

10 Weighted Responses to Interaction Modifications - Increase in Test Score Correlation

11 Overall 'Interactiveness' - Increase in Test Score Correlation 60

12 Weighted 'Interactiveness' - Increase in Test Score Correlation...... 60

13 Revised Weighted 'Interactiveness' - Increase in Test Score

Correlation 61 


\section{LIST OF FIGURES}

\section{FIGURE}

1 Comparison of Subjects' Interaction and Increase in Test Scores... 59 


\section{CHAPTER I}

\section{INTRODUCTION}

This research is a case study of twelve female Japanese English as a Second Language (ESL) students and their American instructor in a content based ESL course. The purpose of the study is to describe the interaction modifications, for the purpose of negotiation of meaning, used by Japanese students during student-student and student-teacher interactions in ESL classrooms. By describing this process as it actually occurs in the ESL classroom, a better understanding of student-student and studentteacher interaction will be achieved.

Data for this study were collected using field notes and audio tapes of classroom observations. The communicative orientation of language teaching (COLT) (Allen, Frohlich, \& Spada, 1984; Spada \& Frohlich, 1995) observation scheme was used to code the students' and teacher's interaction modifications according to their functions. Students' responses to the interaction modifications were also analyzed according to their length and complexity.

The main focus of the study is on the extent to which Japanese students take part in or initiate interaction modifications for the purpose of negotiation of meaning. Since comprehensible input and interaction modifications have been shown to have a positive effect on SLA, the 
researcher was interested in observing to what extent Japanese learners use interaction modification strategies.

This case study is different from most of the previous research studying the effect of interaction modifications on SLA because it takes into account the role of cultural values. In the case of Japanese students, cultural values, as expressed through communication strategies, may tend to affect the number and type of interaction modifications employed. Cultural values may also influence the purpose for which Japanese students use interaction modifications.

\section{Theoretical Foundation}

Input and interaction play an important role in second language acquisition (SLA). Through simplification or modification of input, modification of interaction, or both, learners are facilitated in gaining language proficiency. Input that is meaningful and comprehensible to the learner may provide data for interlanguage hypothesis testing and reformulation. Through interaction modifications, learners are able to negotiate for meaning in order to obtain the proper level of input for their stage of development. Also, learners can further test their interlanguage hypotheses by forming output based on their interlanguage rules and receiving feedback on this output. During interaction modifications, this cycle of negotiating of meaning for comprehensible input, interlanguage 
hypothesis testing and reformulation, and output formulation based on these IL rules is repeated. As Hatch (1978) states, "One learns how to do conversation, one learns how to interact verbally, and out of this interaction, syntactic structures develop" (p. 404).

Long (1985) empirically shows that modification (both linguistic and interactional) facilitates comprehension. Linguistic modification can take the form of simplification of lexical items and syntactic structures, as found in some forms of foreigner talk (FT). Several studies have shown that in addition to linguistic simplification, FT contains grammatical adjustments that, while still being more syntactically complex than simplified input, utilize omission, expansion, replacement, and rearrangement (Long, 1983). The primary function of FT is to promote effective communication, although it may indirectly serve a teaching function by drawing the learner's attention to certain syntactic forms, and semantic or pragmatic meaning.

Comprehensible input can allow the learner to focus on the meaning rather than the form of the message. This reduced cognitive load can provide the learner with the opportunity of taking part more fully in a conversation.

Some researchers (Long, 1981, Ellis, 1985) hypothesize that participation in conversation that includes negotiation of meaning through interaction modifications is a necessary condition for second language acquisition. Hence, comprehensible input may become data for the learner's interlanguage rule formation. However, this process does not necessarily 
occur in all instances where comprehensible input is obtained by the learner. As Ellis (1985) notes, "Input is the L2 data that the learner hears; intake is that portion of the L2 that is assimilated and fed into the interlanguage system" (p. 159). Thus, the learner must not only comprehend the input but also notice a difference between it and his or her own interlanguage (IL) rules. The learner must then restructure his/her IL rules to fit those of the input.

Since they appear to play an important role in SLA, these interaction modifications leading to comprehensible input need to be encouraged in the language classroom. However, this may not be occurring in many language classrooms. Pica and Long (1986) found that few moves to modify interaction for the purpose of achieving comprehension occur in the language classroom, even in those classrooms considered to be highly communicatively oriented or those geared toward the promotion of skills and strategies for comprehension. When compared with informal conversations between native speakers (NSs) and non-native speakers (NNSs), the amount of negotiation for meaning that occurs in the second language classroom setting is much smaller as measured by the significantly lower number of conversational adjustments made by teachers. These findings support those by Long and Sato (1983), who found that the second language classroom setting provides less opportunity for negotiation of meaning than informal NS-NNS conversations outside the classroom. 
It should also be noted that not all ESL/EFL students interact in the same manner or amount. This behavior could adversely affect L2 acquisition. If learners do not take part in, or initiate, interaction modifications leading to comprehensible input, they may not have the raw data needed for interlanguage development. Of particular interest to the present study, Japanese ESL/EFL students are often viewed as being shy, uncommunicative, and hesitant to initiate interaction or negotiate for meaning in a classroom setting. If this is the case, it would be useful to know why Japanese students behave in this manner. This information would permit second language researchers and teachers to determine what culturally appropriate methods can be used by language teachers to encourage the use of interaction modifications by Japanese students. The topics presented in this section will be more fully developed in chapter two.

\section{Definitions}

Input: Language addressed to the second language (L2) learner either by a native speaker (NS) or by another L2 learner.

Interaction: Discourse jointly constructed by the learner and his or her interlocutors.

Interaction modifications: Devices used by NSs and NNSs to prevent or repair breakdowns in communication and to sustain a conversation. These devices include confirmation checks, comprehension checks, clarification requests, repetition, and expansion.

Clarification requests: Any expression that elicits clarification of the preceding utterance. Moves by which one 
speaker seeks assistance in understanding the other speaker's preceding utterance through questions (including wh-, polar, disjunctive, uninverted with rising intonation, or tag), statements such as 'I don't understand', or imperatives such as 'Please repeat'.

Confirmation checks: Any expression immediately following the previous speaker's utterance intended to confirm that the utterance was understood or heard correctly. Move by which one speaker seeks confirmation of the other's preceding utterance through repetition, with rising intonation, of what was perceived to be all or part of the preceding utterance.

Comprehension checks: Any expression designed to establish whether the speaker's own preceding utterance has been understood by the addressee. Moves by which one speaker attempts to determine whether the other speaker has understood a preceding message.

Self-repetitions:

a) Repairing: The speaker repeats or paraphrases some part of her own utterance in order to help the addressee overcome a communication problem.

b) Preventive: The speaker repeats or paraphrases some part of her own utterance in order to prevent the addressee experiencing a communication problem.

c) Reacting: The speaker repeats or paraphrases some part of one of her previous utterances to help establish or develop the topic of conversation.

Other-repetitions:

a) Repairing: The speaker repeats or paraphrases some part of the other speaker's utterance in order to help overcome a communication problem.

b) Reacting: The speaker repeats or paraphrases some part of the other speaker's utterance in order to help establish or develop the topic of conversation. 
Intake: That part of the input that is processed or "let in". Not all the available input is processed by the learner, either because some of it is not understood or some of it is not attended to.

\section{Research Questions}

This case study will investigate the interaction between Japanese ESL students and their American instructor in order to answer the following questions (note: interaction modifications refer specifically to confirmation checks, comprehension checks, and clarification requests):

1. What interaction modifications do Japanese ESL learners use in teacherfronted classes?

2. What interaction modifications do Japanese ESL learners use in pairwork or small-group situations?

3. Is an increased use of interaction modifications positively correlated with an increase in English proficiency as measured by increase in Michigan Test of English Language Proficiency (Michigan test) scores?

4. Does the amount of use of some interaction modifications have a greater positive correlation with increase in English proficiency, as measured by increase in Michigan test scores, than the amount of use of other interaction modifications? 
5. How do Japanese ESL learners respond to clarification requests, confirmation checks, and comprehension checks (e.g., single word, full or partial repetition, or reformulation)?

6. Is there a positive correlation between the manner in which Japanese ESL learners respond to interaction modifications (e.g., single word, full or partial repetition, or reformulation) and increase in English proficiency, as measured by increase in Michigan test scores?

\section{Summary}

In summary, this study will give a descriptive analysis of studentstudent and student-teacher interaction, and student's responses to interaction modifications in a content based ESL class. Focusing on interaction modifications and the type of responses they elicit, along with a consideration of cultural influences, will permit the researcher to make recommendations specifically suited for Japanese students in ESL classrooms. If the use of interaction modifications is found to be positively correlated with an increase in English language proficiency, ESL teachers could enhance their teaching skills and help their students improve their language proficiency by using interaction modifications themselves and encouraging interaction modification use by their students. 


\section{CHAPTER II \\ REVIEW OF THE LITERATURE}

Interaction modifications are a major means for non-native speakers to obtain comprehensible input through negotiation for meaning. In studies done outside the classroom, interaction modifications have been found to play an important role in non-native speaker listening comprehension and, to a lesser extent, L2 acquisition.

The content of this chapter is designed to give an overview of the issues concerning interaction modification and its applicability to second language acquisition. The literature reviewed is intended to provide a sense of the perspectives and approaches taken by researchers, and exposure to the variety of studies attempting to provide empirical evidence for the role of interaction modifications on comprehension and L2 acquisition. Also, an examination of the role that culture may play in the use of interaction modifications will be provided.

The first section discusses the comprehensible input hypothesis. The next section examines the interaction hypothesis. The following section discusses counter theories to the interaction hypothesis. Modifications to the interaction hypothesis will then be reviewed. The following sections provide empirical evidence for the interaction hypothesis claims regarding comprehension and acquisition. 
The culture section of this review will discuss the Japanese sociocultural values of group orientation and harmony within a group. The supporting section will examine examples of communication strategies, for example, taciturnity, enryo, and sasshi, resulting from these cultural values. Finally, the effect of culture on interaction modifications will be discussed.

\section{Input Hypothesis}

Krashen's input hypothesis $(1977,1980,1983,1985)$ argues for the importance of input comprehension to second language acquisition (SLA). Krashen $(1977,1980)$ argues that the subconscious process of 'acquisition' (as opposed to the conscious process of 'learning') occurs when the learner is focused on meaning and obtains comprehensible input. He emphasizes the role of simplified input ('simple codes', e.g., foreigner talk (FT) and interlanguage (IL) talk) and of contextual support in making input comprehensible. He also claims that language production plays no direct part in acquisition. Krashen's input hypothesis states that second language (L2) input must both be comprehended and be at one stage above the learner's current level $(i+1)$ in order to be acquired. An added stipulation is that the learner be emotionally receptive to the input, or, in Krashen's terms, the affective filter must be low. Thus, comprehensible input is held to be a necessary, though not sufficient, condition for SLA (Krashen, 1985). 
Chaudron (1985) has pointed out that this formulation still lacks a sufficiently detailed psycholinguistic account of the perceptual mechanisms involved in noticing a gap or what constitutes $i+1$. Chaudron also has noted that since the linguistic scope of this hypothesis has been left unclear by Krashen, we may assume that it refers to all levels of $L 2$ forms (i.e., from syntactic to lexical). It also has been noted by several researchers (see, for example, Larson-Freeman \& Long, 1991) that many of Krashen's claims are not falsifiable, and thus untestable. However, Krashen's input hypothesis has made an important contribution to the study of SLA by stimulating the discussion of the processes involved in acquisition. Long has built on the input hypothesis in developing his interaction hypothesis.

\section{The Interaction Hypothesis}

Long's interaction hypothesis $(1980,1983,1985)$ is an argument for the value of modification to discourse structure, through interaction, for learner comprehension. The interaction hypothesis advances two major claims about the role of interaction in L2 acquisition:

1) Comprehensible input is necessary for $L 2$ acquisition.

2) Interaction modifications that are directed at solving a communication problem help to make input comprehensible.

Thus, Long differs from Krashen on how input is made comprehensible. While acknowledging that simplified input and context can play a role in making input comprehensible, Long stresses the importance of the 
interaction modifications that occur in negotiating meaning when a communication problem arises. In other words, Long's argument is that interactive input is more important than non-interactive input.

Long (1980) discovered that foreigner talk entailed few input modifications (e.g., simplification or elaboration) but numerous interactional adjustments (for the purpose of negotiating meaning, hereinafter referred to as interaction modifications). Long found a statistically significant higher frequency of various interactional features in native speaker (NS)-non-native speaker (NNS) as opposed to NS-NS conversations in tasks that required information exchange. These interactional modifications involved in the negotiation of meaning include clarification requests, confirmation checks, and comprehension checks. Long (1983) defines these modifications as:

Clarification requests - speaker requests help in understanding something the interlocutor has said.

Confirmation checks - speaker attempts to ascertain whether s/he has heard or understood something the interlocutor has said.

Comprehension checks - speaker checks whether the interlocutor has understood something the speaker has said.

These devices provide learners with opportunities to resolve their comprehension difficulties and, therefore, make negotiation of meaning possible. Long (1983) argues that access to comprehensible input is characteristic of all cases of successful first and second language 
acquisition, and greater quantities of comprehensible input seem to result in faster acquisition while a lack of access to it results in little or no acquisition. Therefore, comprehensible input is seen as necessary for acquisition, at least for the beginning learner. In the same study Long argued that modifications to the interactional structure of conversation were "the most important and widely used" ways of making input comprehensible (p.342).

Long (1985) deductively argues that modifications to discourse structure (e.g., negotiated interaction and modified input) indirectly facilitate SLA. He shows that interactional modifications promote comprehension of input and that comprehensible input promotes acquisition. He then deduces that interactional modifications promote acquisition.

There have been objections to the interaction hypothesis, however. Two proposed revisions to the input hypothesis relevant to this discussion are the incomprehensible input hypothesis (White, 1987) and the comprehensible output hypothesis (Swain, 1985). Both suggest that negative feedback, during either comprehension or production, is vital to IL development. White (1987) has argued that, besides comprehensible input, incomprehensible input is also vital to SLA. White also has claimed that when learners encounter input that is incomprehensible because their IL rules do not permit a particular L2 structure, they may be 'pushed' to modify those IL rules to accommodate the structure. Thus, comprehension difficulties can provide important negative feedback to the learner. Swain 
(1985) and Pica, Holliday, Lewis, and Morgenthaler (1989) have argued that, in addition to comprehensible input, comprehensible output is also necessary for SLA. This argument hinges on the fact that learner production sometimes elicits either direct or indirect negative feedback from an interlocutor. If communicative demands are put on the learners to make their output more comprehensible, in the process, they may test and modify their IL hypotheses.

Whether this is a revision or clarification of Long's work is unclear. However, in more recent work Long's theoretical position appears to have developed somewhat to include an account of the role of output in SLA. Long (1989), while continuing to assert that comprehensible input is necessary for acquisition, also clearly recognizes that it may not be sufficient. Second, he acknowledges that interaction promotes $\mathrm{L} 2$ acquisition not only by supplying comprehensible input but also by providing the learner with opportunities for production. Long, like White, Swain, and Pica et al., recognizes that interlanguage development can take place when learners are 'pushed' to improve their output.

\section{Evidence}

Several studies have investigated Long's claims about the effect of interaction on comprehension, and the necessity of comprehension for SLA. 
These studies will be reviewed to see if there is any empirical support for the interaction hypothesis.

Interaction leads to comprehension.

Evidence for the facilitation of comprehension by input modification was reviewed by Parker and Chaudron (1987). The authors analyzed twelve studies comparing NNS comprehension (for both listening and reading). The authors concluded that input elaborations facilitate comprehension at least as much, if not more than, input simplifications, which, they argued, may be unnecessary for optimum comprehension. A similar argument has been made by Pica, Young, and Doughty (1987), who used premodified input in their noninteraction group. When the authors compared their premodified input with the input modification produced during negotiated interaction, they argued that:

A decrease in the complexity of the input did not appear to be a critical factor in comprehension. Indeed, ... interaction resulted in input that was more complex than input that was modified according to conventional criteria of linguistic simplification. (pp. 749-750)

And yet this input led to greater comprehension. Studies by Doughty and Pica (1986), Ellis, Tanaka, and Yamazaki (1994), Gass and Varonis (1985), Long and Sato (1983), Loschky (1988, 1989), Pica and Doughty (1985), Tanaka (1991), and Yamazaki (1991) found similar results: interaction resulted in greater comprehension than either premodified or simplified 
input. Loschky (1989) suggests that opportunities to negotiate meaning may especially aid beginner learners in comprehension.

However, it should be noted that in all of these studies the opportunity for negotiation led to considerable repetition and rephrasing with the result that interactionally modified input provided the learners with much more input than was available in the unmodified and premodified input. Therefore, it is impossible to tell whether the advantage shown for the interactionally modified input arose as a result of the greater input which it supplied or as a result of the opportunities for negotiating meaning. It may be that the premodified input would have worked as well as, or even better than, the interactionally modified input had it been as plentiful.

Subsequent studies by Pica $(1989,1992)$ addressed this problem. The studies compared the effects of interactionally generated input with premodified input (based on the interaction input) which contained the same amount of original and repeated input and took the same length of time to present. In this way Pica was able to use equal measures since the two conditions differed only in whether there were opportunities for negotiation of meaning. Pica found no statistically significant difference in comprehension scores. However, Pica noted that for those learners who were rated as having lower comprehension ability by their teachers, the opportunity to interact was beneficial. Pica concludes that opportunities for negotiation may be most beneficial for leamers in the early stages of SLA. 
These findings support earlier conclusions that negotiation of meaning may benefit lower level learners more than more advanced ones. It should also be noted that Pica's 1992 study found no significant differences in the comprehension of learners who observed negotiation taking place but did not actually negotiate themselves, and those who actively participated. In this study, the subjects were divided into three groups: (1) Negotiators who were encouraged to ask for clarification and confirm their comprehension, (2) Observers who carried out the same task, at the same time, as the negotiators, but could only listen, and (3) Listeners who performed the same task after groups one and two were finished. The listeners' instructions were constructed so that they contained the same amount of original and repeated input, and took the same amount of time to present as the directions produced when the negotiators and observers carried out the task. Pica found no statistical difference in comprehension scores among the three groups. Thus, negotiated input may benefit learners in comprehending direction input whether they are Negotiators, Observers, or Listeners.

It would appear that while negotiation of meaning through interaction facilitates comprehension, it is not significantly superior to other means of increasing comprehension. The importance of interaction lies in the fact that it can be within the control of the learner. 
Counter evidence to interaction leading to comprehension.

The claim that interactional modifications aid comprehension has met with opposition, however.

First, there is some evidence to suggest that what appears to be the negotiation of meaning may not be anything of the kind. Both Hawkins (1985) and Aston (1986) have pointed out that learners may sometimes feign comprehension after negotiation rather than continue to demonstrate incomprehension to their interlocutors. Hawkins (1985) found that in $50 \%$ of the responses for which retrospective data were available, comprehension had not in fact taken place.

Second, it has been pointed out that interactional modifications occur for other purposes than for negotiating meaning. Aston (1986) has argued for a social perspective on what he calls 'trouble shooting procedures' to complement the psycholinguistic perspective of the interaction hypothesis. He argues that modifications to the structure of interaction may occur when the participants need to achieve 'a formal display of convergence'. In such cases, Aston suggests, they may go through a 'ritual of understanding or agreement' in order to show that the interaction has been successful

Third, following on Hawkins' and Aston's observations, the claim that it is the quantity of interactional modifications that matters has been challenged. Both Derwing (1989) and Ehrlick, Avery and Yorio (1989) found that NSs who include more information when addressing NNSs 
('embroiderers', Ehrlick et al.) were less successful in communication with the NNSs than were NSs who did not elaborate as much ('skeletonizers'). Thus, the mere number of meaning negotiations within an interaction may not be a good predictor of the quality of comprehensible input. Ehrlick et al. conclude that 'skeletonizing' is more likely to result in comprehensible input. These studies indicate that it is not so much the quantity as the quality of interaction that affects comprehension. Ellis (1991) concludes that there seem to be two possibilities regarding the relationship between interactional modifications and comprehension:

(1) Interactional modifications help learners to comprehend difficult material. They appear to aid comprehension to a greater extent than premodified input.

(2) Precisely when and how interactional modifications work for comprehension is still poorly understood, but it is becoming clear that it is the quality rather than the quantity that matters. (p. 29)

Thus, the claim that interactional modifications facilitate comprehension seems to be well supported. The claim that comprehension is necessary for acquisition remains in doubt, however.

\section{Comprehensible input is necessary for acquisition}

The evidence for the necessity of comprehension for acquisition is primarily indirect. Long (1983b), Larsen-Freeman and Long (1991), and Krashen $(1985 ; 1989)$ cite literature relating to ten sources that they claim support the claim that comprehensible input contributes to acquisition. 
Overall, this evidence supports the assumption that learners need to understand input in order to learn from it. It is less clear, however, whether this evidence warrants the claim that comprehensible input is a causative factor in L2 acquisition. In many cases, the evidence is correlational in nature. For example, caretaker and foreigner talk co-occur with successful acquisition. Thus, this evidence cannot be said to demonstrate that comprehensible input causes acquisition.

Direct evidence for the necessity of comprehension for acquisition would be provided by learners who, though exposed to large doses of L2 input, were unable to comprehend it and showed no evidence of acquisition. Good examples of this come from children whose only input, though frequent, is provided by television or radio (Snow et al., 1976). Stronger evidence is provided by Jim, the hearing child of deaf parents, for whom daily TV watching was his only source of English input (Sachs et al., 1981). This evidence seems to suggest that this type of input, presumably unmodified and generally incomprehensible, is insufficient for much acquisition to occur. This may be because such incomprehensible input does not facilitate the noticing process. As will be discussed later, this process of noticing may play an important role in the reformulation of IL rules by learners. 


\section{Counter evidence.}

Evidence against a one-to-one linear relationship between $L 2$ comprehension and the acquisition of $L 2$ syntax comes from recent studies by Doughty (1991) and Locshky (1989). Doughty found that differences in reading comprehension between learners in two treatment groups were not matched by differences in acquisition. Both groups showed equally significant pretest/posttest gains. From the viewpoint of the input hypothesis, the question is why the group evidencing less input comprehension acquired as much as the group evidencing more. A possible explanation is that there is an as yet undetermined minimal level of comprehension below which acquisition is impossible, but above which differences in comprehension have little effect on SLA. This explanation is appealing because it seems to agree with earlier findings that negotiation of meaning may be especially beneficial for lower level learners. However, Loschky, in a study of Japanese article acquisition, also found no evidence to support the theory that greater L2 comprehension leads to greater acquisition.

Sharwood Smith (1986) argues that the processes of comprehension and acquisition are not the same. He suggests that input has a 'dual relevance', "there is input that will help the learner to interpret for meaning and there is input that she will use to advance her interlanguage" (p. 241). Sharwood Smith contends that in the case of comprehension, surface input 
is only briefly registered, as the learner rapidly recodes into "deeper semantic and pragmatic codes" in which the message is then stored. In the case of acquisition, the learner needs to undertake both a surface structure analysis and a semantic representation of the input. The input has to be held in memory long enough for a comparison between its representation and whatever representation is provided by the rules of the learner's IL to be carried out. Without such a comparison no restructuring of the current IL rules can take place. Faerch and Kasper (1986), Schmidt (1990), Schmidt and Frota (1986), Spada and Lightbown (1989), and Spada (1987) take a similar position regarding noticing, restructuring, and acquisition. These researchers argue that acquisition only occurs when there is a 'gap' between the input and the learner's current IL and, more importantly, when the learner consciously notices such a gap.

Thus, Long's (1983) conclusion, that comprehension is necessary for acquisition "because the predictions it makes are consistent with the available data" (p. 341) does not appear to be warranted. Rather, the studies cited support the position that comprehensible input facilitates, rather than is necessary for, acquisition.

Simply because the evidence does not support Long's claims does not mean that the input hypothesis needs to be completely discarded, however. A modification of the interaction hypothesis explanation of how interaction facilitates language acquisition has been proposed by Ellis 
(1991). Ellis' explanation is based on 'noticing', which, as mentioned earlier, is an important process in SLA. This explanation will be reviewed, along with the importance of the different strategies involved in negotiation, in the following discussion.

\section{How Interaction Facilitates SLA}

Ellis (1991) provides an addition to the input hypothesis which gives a theoretical account of how input made comprehensible through interactional modification results in acquisition. He states that "The process of acquiring an L2 involves three basic procedures: (1) noticing, (2) comparison and (3) integration" (p. 30). Noticing is when the learner consciously attends to linguistic features in the input. This entails perception and storage in short term memory. Thus, a feature that is noticed becomes 'preliminary intake' (Chaudron, 1985). Comparison also involves only short term memory. The learner identifies the difference between features noticed in the input and features in his/her own output. Integration occurs when the learner forms new IL rules based on the comparison of the input and the current IL rules, and stores these changes in long term memory. Therefore, using Chaudron's (1985) terminology, integration results in 'final intake'. For acquisition to occur, all three procedures must take place. However, simply because a learner has noticed some feature in the input, and carried out a comparison with his/her own IL rules, does not mean that integration will 
take place. Psycholinguistic constraints of various kinds govern when new linguistic material is incorporated into the learner's interlanguage (Pienemann, 1989). The role of input derived through interaction appears to be primarily that of facilitating the processes of noticing and comparison.

According to Schmidt (1990), the process of noticing is necessarily a conscious one. Conscious noticing, however, is not the same as deliberate attending. Noticing can take place either intentionally or inadvertently. Also, noticing does not require focal attention. When taking part in a conversation, for instance, the learner may be primarily focused on the message content, but may also pay peripheral attention to striking linguistic features in the input. Under certain conditions, the learner may bring these features into focal attention. Lennon (1989) has documented how the advanced learners he studied appeared to switch their attention between trying to communicate to trying to learn by consciously attending to input features even within the course of a single interaction

The process of comparison is also potentially a conscious one, although it may often take place subconsciously. Schmidt and Frota (1986) provide several examples of how features that were noticed in the input and compared to current output subsequently appeared productively in the subjects' conversational output.

Of key interest is what induces a learner to notice features in the input and then compare them to his/her current output. It is here that a role 
for comprehensible input and interaction appears likely. Modified input may be effective in drawing a learner's attention to features that would otherwise be ignored. This might occur in two principle ways: (1) by increasing the frequency of specific forms at particular times (Wells, 1985), and (2) by constructing messages in such a way that certain features become prominent in the input (by placing them in utterance initial position).

The processes of noticing and comparison, then, may be facilitated when input is comprehensible and when interactional modification is possible. It is important to recognize, however, that there are likely to be a number of factors in addition to interactional modifications that govern if and when these acquisitional processes take place (Schmidt, 1990). These factors may include:

1) Task demands (i.e., the instructional task causes the learner to attend to certain linguistic features because these are important for acquisition).

2) unusual features (features that surprise the learner. Such features may work in similar ways to deviations in literary texts).

3) markedness (features that are relatively unmarked may be easier to notice than features that are more marked). 
4) The learner's $L 1$ ( $L 2$ features that match $L 1$ features may be more noticeable, at least in the earlier stages of acquisition).

5) Individual learner differences (factors such as aptitude and motivation may influence whether or not a learner attends to new linguistic features in the input).

More recent work on negotiated interaction has sought to show how learners can be 'stretched' by obliging them to make their own output more comprehensible. Several researchers (Ellis, 1991; Pica et al., 1995) have argued that certain interactional modifications may be more helpful than others in 'stretching' the learner's skills to produce comprehensible output. For example, requests for clarification 'stretch' learners by making them clarify what they have said, whereas confirmation checks do not because the interlocutor solves the communication problem for the learner.

\section{$\underline{\text { Culture }}$}

It appears safe to assume that interaction modification through the negotiation of meaning is a useful tool in SLA. However, not all learners may employ these interaction strategies due to cultural reasons. There is no guarantee that the negotiation of meaning proceeds similarly in other languages. We do not know whether the same kinds of modifications occur cross-linguistically. A study by Kitazawa (1990) has reported considerable 
problems in identifying and classifying the interactional modifications described by Long and Pica in Japanese conversations involving learners. Sato (1981) found that Asians self initiated less, and interacted less than non-Asian learners in an ESL classroom setting. Thus, it seems that culture may play an important role in SLA with respect to the frequency and type of interaction modifications employed by learners. In the following discussion some of the aspects of Japanese culture that might tend to limit learner interaction will be discussed.

Japanese students may tend to behave differently than other ESL/EFL students in interactions, with respect to negotiation of meaning, due to the effects of cultural influences. These influences may affect the type and number of interaction modifications employed by Japanese students. The following review will examine the Japanese socio-cultural values of collectivism and group harmony, and some communication strategies, such as enryo, sasshi, and taciturnity, resulting from these values. In addition, their effect on inter-personal interaction will also be discussed.

\section{Group Harmony}

One of the most important values in Japanese society is group harmony, or wa. It affects and influences all types of behavior in Japan. Nakane (1977) states that "The Japanese ethic puts high value on the 
The differences in the education systems in the U.S. and Japan are reflected in the differences in the roles of teacher and student. In Japan, group harmony, uniformity and respect for the teacher are valued. Students address teachers as sensei, a term of respect. Neither teachers nor students should ever be made to lose face by directly questioning a statement or action (Kurogi, 1990). Also, as Watanabe (1990) points out, Japanese teachers rarely use group discussion as a means of studying school subjects. Hence, traditional, teacher fronted classes prevail in Japan When Japanese encounter difficulties in group discussions with native English speakers, it may be due to their listening comprehension skills, but may also be a result of the differences between Japanese and Americans in styles of explanation and presentation of arguments (Watanbe, 1990). One reason why Japanese students are perceived as being quiet is that, when faced with non-comprehension, they may tend to sit back, listen attentively, and refrain from interrupting in order to ask for clarification. With respect to the overall focus of this paper, the difference in use of interaction modifications is important.

Japanese students may tend to use clarification requests not only when they do not understand, but also to encourage someone to speak more. This is directly related to the Japanese value of sasshi. If a Japanese perceives that another member of the group has something to add to the conversation, they may use a clarification request to encourage 
them to say more. With regard to confirmation requests, Watanabe (1990) notes that:

Request for confirmation can also be related to the fact that Japanese value harmony. Checking, with the other members, if one is correct is one strategy to avoid conflict. (p. 267)

Therefore, Japanese use interaction modifications not only as a means of negotiation of meaning, but also to maintain group harmony.

In the preceding review of the different aspects of Japanese culture that may tend to influence interaction modifications, only a few of the many facets of Japanese culture have been investigated. Also, the parts of Japanese culture that were examined were done so from a non-Japanese perspective. As noted by Jorden (1992), culture can be separated into acquired culture and learned culture. Although non-Japanese are able to learn about Japanese culture, they may not be able to fully appreciate all of its intricacies and effects. 


\section{CHAPTER III}

\section{METHODOLOGY}

\section{Subjects}

The subjects of this study are twelve female English as a second language (ESL) students from Japan. They have previously studied English for eight years in Japan. At the beginning of the study, the subjects had been living in the US for approximately four months. The subjects are all members of a larger group of Japanese students in a special Extended Studies program at a university in the Northwest. Prior to coming to the US, the students were attending a four year college in Japan. Some of the subjects elected to stay in the US for six months, while the remainder will stay for nine months. Upon completion of the program, the subjects will return to Japan as Juniors to complete their college program. The subjects range from twenty to twenty-one years of age. The students were also enrolled in regular English as a second language (ESL) classes in an ESL program at the time of the study. They were placed in either level one (L1) or level two (L2) classes in this program based on scores from a retired version of the Michigan Test of English Language Proficiency, hereafter referred to as the Michigan Test, and other criteria. These students were selected for this study based on their selection of a special Extended Studies content based class, Basic Resources for Internet Explorers, during 
the Summer term of 1996. Table 1 presents descriptive data about the twelve subjects.

Table 1

Subjects' Descriptive Data

\begin{tabular}{clccc}
\hline Subject & Gender & Age & $\begin{array}{c}\text { Michigan Test } \\
\text { score (March) }\end{array}$ & $\begin{array}{c}\text { ESL } \\
\text { placement }\end{array}$ \\
\hline S1 & Female & 21 & 21 & L1 \\
S2 & Female & 20 & 27 & $\mathrm{~L} 1$ \\
S3 & Female & 20 & 31 & $\mathrm{~L} 1$ \\
S4 & Female & 21 & 28 & $\mathrm{~L} 1$ \\
S5 & Female & 20 & 35 & $\mathrm{~L} 2$ \\
S6 & Female & 21 & 32 & $\mathrm{~L} 2$ \\
S7 & Female & 20 & 33 & $\mathrm{~L} 1$ \\
S8 & Female & 20 & 30 & $\mathrm{~L} 1$ \\
S9 & Female & 21 & 39 & $\mathrm{~L} 2$ \\
S10 & Female & 20 & 27 & $\mathrm{~L} 2$ \\
S11 & Female & 20 & 40 & $\mathrm{~L} 1$ \\
S12 & Female & 20 & 34 & $\mathrm{~L} 2$ \\
\hline
\end{tabular}

Setting

The instructor for the course in which the data were collected has several years of experience teaching ESL/EFL. He has been teaching English to Japanese students in Japan for the past two years and is especially knowledgeable about the Internet and using computers as an aid to language learning.

The course, Basic Resources for Internet Explorers, is a content based class. The goal of the course is to use English as a medium for learning about the Internet so that the students can continue to use 
computers and the Internet on their own after returning to Japan. Some of the course topics included: e-mail, the UNIX system, conducting an Internet search, cyber cafes, and building a home page for the world wide web. The class met for one hour and fifty minutes, five days a week for five weeks.

The primary classroom was a Macintosh microcomputer lab. The class also occasionally met in a small conference room in the Extended Studies building. The students were also required to do homework outside of class time. To do this homework they had to go to other microcomputer labs on campus.

\section{Instruments and Materials}

The communicative orientation of language teaching (COLT) (Allen, Frohlich, \& Spada, 1984; Frohlich, Spada, \& Allen, 1985; Spada \& Frohlich, 1995) observation scheme was used to code the data from the classroom tape transcripts. The COLT was developed to examine the relationships between instructional input and learning outcomes. The developers of this instrument believe that it is not enough for researchers to simply describe what takes place in the language classroom. There is a need to discover what features of instruction are most beneficial for learning. Therefore, research needs to focus on both process and product variables. The intent is for the instrument to describe instructional behaviors that are valid indicators of learning processes and outcomes. 
The COLT is divided into two parts: $A$ and $B$. Part $A$ is coded in 'real time' while the observer is in the classroom. Part A focuses on describing the classroom activities, participant organization, content, student modality, and materials. Transcripts of a class can also be used to verify the coding for part A. Part B is coded from tape transcripts of the observation period. It provides a detailed description of the verbal interactions that take place between teacher-student(s) and student-student groups. Part B codes seven communicative features: use of target language, information gap, sustained speech, reaction to form or message, incorporation of preceding utterance, discourse initiation (by students), and restriction of form (imposed on students by the teacher, textbook, or task).

The developers of the COLT scheme have allowed for its adaptation to meet the specific needs of individual researchers. In chapter six of COLT Coding Conventions, Spada and Frohlich (1995) provide several examples of how revisions and adaptations have been made to the scheme to accommodate specific research purposes. In some of the COLT studies only one part of the scheme was used. For example, one group of researchers used an expanded version of the reaction to form/message category on Part B in a process-product study. This was the technique used in the present study as well. The main focus was on the incorporation of student/teacher utterances category on Part B. The feature, incorporation of student/teacher utterances, is further broken down into the following 
categories: correction, repetition, paraphrase, comment, expansion, clarification request, and elaboration request. Definitions for these categories as found in Spada and Frohlich (1995) are given below:

Correction: An attempt to provide the speaker with the information that they have provided a linguistically incorrect utterance.

Repetition: Full or partial repetition of the previous utterance(s).

Paraphrase: Reformulation of the previous utterance(s), including translation.

Comment: Any positive or negative response, but not correction, to the previous utterance(s). Either form or message related.

Expansion: Any extensions of the information provided in a preceding utterance or the addition of information which is related to it.

Clarification request: Requests which indicate that the preceding utterance was not clearly understood and a repetition or reformulation is required.

Elaboration request: Any request for further information related to the subject matter of the preceding utterance.

The feature incorporation of student/teacher utterances was expanded to investigate the effects of particular categories of interaction on second language (L2) development. As noted by Spada and Frohlich (1995):

Although the categories under Incorporation of student/teacher utterances allow for some distinction between the kinds of interactions which take place between teachers and students, it is important to emphasize that these categories are not 
sufficient to describe every feature of an utterance which occurs in the discourse ... The categories also do not permit distinctions in the kinds of Clarification requests one might observe (i.e. confirmation requests versus comprehension checks). Clearly, more categories would be needed if one wanted to do a more detailed discourse analysis of classroom language. (pp. 86-87)

In order to more closely match the categories of interaction (modification) techniques used by Long (1983a) and Pica and Doughty (1985), for this study the categories of confirmation checks and comprehension checks (see chapter one for definitions) were added to the feature incorporation of student/teacher utterances.

The materials used to record the lessons consisted of a tape recorder, a sound mixer, four microphones with stands, and microphone cords long enough to permit the distribution of the microphones.

\section{Procedure}

The data for this study were collected through daily audio-taping of the subjects and their teacher interacting in class. Over the five week period of the course, nine tapes were made of the hour and fifty minute classes. Of the nine tapes, six were recorded in the computer lab and three were recorded in the conference room. Field notes were also taken during the classes to provide additional information regarding the content of the class and classroom interactions. 
In an attempt to make the subjects feel more comfortable with the researcher's presence in the classroom, initially no field notes were taken or audio recordings made. After two class periods the researcher began to take notes. At the third class meeting that was observed, a small cassette recorder and hand microphone were used to record the classroom interaction. Finally, at the fifth class meeting observed, the entire recording system of recorder, sound mixer, and four microphones was introduced into the classroom.

The microphones were placed to cover general areas of the respective classrooms, rather than discrete groups of subjects. This procedure was more effective in the conference room, since all the subjects were grouped around one large conference table. In the computer lab the coverage of the microphones was limited by the length of the microphone cords. This meant that one row of computers along the outside wall was not directly covered. However, since the students randomly chose where to sit every day, all the students were recorded the majority of the time. By using the sound mixer, the researcher attempted to isolate discrete groups of students to better record student-student and teacher-student interaction. At these times the members of these groups were noted in the field notes.

The audio tapes collected during the observation periods were indexed according to date and location. The subjects' and instructor's speech on the tapes was transcribed in standard English orthography. The 
tapes were transcribed in their entirety. Since the researcher was interested in how conversations are structured in terms of interaction, a time-sampling procedure would have fragmented the data by not fairly representing each student's interactions. This would make the data inappropriate for coding in this manner. The subjects' grammatical mistakes were transcribed intact. This was done to assist in explaining the nature of any miscommunication and resulting interaction for negotiation of meaning. Nonverbal communication, as noted in the researcher's field notes, was also indicated on the transcripts. This was important as an aid to understanding the context of the interactions since the COLT does not allow for coding of nonverbal behavior.

\section{Analysis of Data}

The analysis of the data for the study is confined to the conversational interaction modifications among the students and between the students and instructor recorded in the corpus. From the tape transcripts, the researcher decided that five tapes (tapes 3-7) provided the most extensive evidence of these interactions. The remaining tapes consisted mainly of instructions to the entire class by the teacher or special guest speaker, with minimal interaction taking place. Therefore, five of the nine tapes (tapes 3-7) were coded and analyzed. (See appendix $C$ for a sample portion of the corpus.) 
To determine inter-rater reliability, one of the hour and fifty minute tapes was also coded by another TESOL graduate student. Agreement between the two coders for Part B of the COLT was .87. Agreement between the coders for the specific features of interest was .91 . The individual turns for the instructor and each subject were compared separately when determining agreement rather than overall totals for each category. Use of cell agreement is a conservative measure because it requires that each item be scored independently rather than simply considering group totals for each category.

Although the tape transcripts were coded for part B of the COLT in its entirety, only certain features of interest were quantified and analyzed for this study. These features of interest include discourse initiation, target language, reaction to form/message, and incorporation of student/teacher utterances. The discourse initiation feature was analyzed based on the number of self-initiated turns divided by the total number of student turns. This was done for individual students and the class as a whole. Target language was analyzed based on the proportion of L1 and L2 use, again by individual students and the entire class. Reaction to form/message and incorporation of student/teacher utterances were analyzed in three ways:

1) each category was calculated as a proportion of its main feature per class meeting for each student and the entire class.

2) percentage of use of each category for each feature for the overall course for every student and the entire class. 
3) double coding: analysis of combination of feature/categories, for example message-clarification request as compared with form-clarification request.

Additionally, the subjects' use of type of interaction modification was tallied for each lesson observed. The subjects' type of response to each type of interaction modification was coded and tallied as single word, partial or whole repetition, or reformulation. In addition, a global score of 'interactiveness' was calculated for each student by adding their total number of interaction modifications and their total number of responses to interaction modifications. 


\section{CHAPTER IV}

\section{RESULTS}

This chapter presents the findings of the data analyses. The chapter begins with an explanation of the statistical tests performed on the data. Then, the results of the data analysis on subject use of interaction modifications are presented. Next, the results for the subjects' response to interaction modifications are given. Finally, the results of the analyses of the subjects 'interactiveness' are presented.

\section{$\underline{\text { Statistical Tests }}$}

The Spearman Correlation Coefficient and Pearson's R were calculated to compare subjects' use of interaction modifications and increase in Michigan Test scores. However, after initial analysis, no correlation was found. Since test scores from the CELT (Comprehensive English Language TEST) test were also available, the increase in CELT test scores was also used in the correlation statistics (see appendix $A$ for the subjects' raw test score data, appendix B for an example of the CELT test). The subjects took the Michigan Test in March and August of 1996, and the CELT test in June and August of 1996. Pearson's $R$ is a measure of linear association between two variables. The product-moment correlation coefficient, $R$, that this test returns reflects the extent of a linear relationship 
between two data sets. The value of $R$ ranges between -1 (a perfect negative relationship in which all points fall on a line with negative slope) and +1 (a perfect positive relationship in which all points fall on a line with positive slope). A value of zero indicates no linear relationship. The Spearman Correlation Coefficient is a product-moment correlation coefficient similar to Pearson's R. It takes into account both the amount of disagreement between pairs of data and the degree of disagreement. Because of the small sample size $(n=12)$ and the nature of the data, the nonparametric Spearman rank correlation is the more appropriate test. Although the Spearman correlation is more conservative, the Pearson correlation was also calculated in order to provide support for the Spearman correlation results.

\section{Subject Use of Interaction Modifications}

Of the five tapes from the classroom observations that were transcribed and coded for analysis, two were from teacher-fronted settings, two were from small group or pair work situations, and one was divided, by a break, into both types of settings. Thus, the results presented for each type of setting represent approximately equal duration times. Table 2 shows the frequencies and total number of interaction modifications used by the twelve subjects in teacher-fronted classes. The subjects did not use any comprehension checks in teacher-fronted classes. 
Table 2

Subjects' Use of Interaction Modifications in Teacher Fronted Classes

\begin{tabular}{ccccc}
\hline Subject & $\begin{array}{c}\text { Clarification } \\
\text { Requests }\end{array}$ & $\begin{array}{c}\text { Confirmation } \\
\text { Checks }\end{array}$ & $\begin{array}{c}\text { Comprehension } \\
\text { Checks }\end{array}$ & Total \\
\hline S1 & 0 & 0 & 0 & 0 \\
S2 & 0 & 0 & 0 & 0 \\
S3 & 0 & 0 & 0 & 0 \\
S4 & 0 & 1 & 0 & 1 \\
S5 & 1 & 1 & 0 & 2 \\
S6 & 1 & 0 & 0 & 1 \\
S7 & 1 & 0 & 0 & 1 \\
S8 & 1 & 0 & 0 & 1 \\
S9 & 0 & 1 & 0 & 1 \\
S10 & 0 & 0 & 0 & 0 \\
S11 & 0 & 0 & 0 & 0 \\
S12 & 0 & 0 & 0 & 0 \\
\hline Total & 4 & 3 & 0 & 7 \\
\hline
\end{tabular}

Table 3 shows the frequencies and total number of interaction modifications used by the twelve subjects in small group or pair-work situations. The number of clarification requests used ranged from zero requests by subjects $S 10$ and $S 12$, to five requests by subject $S 6$. The number of confirmation checks used ranged from zero checks by subjects $\mathrm{S} 8$ and $\mathrm{S} 11$, to four checks by S6. Subjects used clarification requests over four times (4.25) more often in small group or pair-work situations than in teacher-fronted classes. Subjects used confirmation checks over five times (5.33) more often in small group or pair-work situations than in teacher- 
fronted classes. As in the case of teacher-fronted classes, the subjects did not use any comprehension checks in small group or pair-work situations. Table 3

Subjects' Use of Interaction Modifications in Small Group/Pair Work

\begin{tabular}{ccccc}
\hline Subject & $\begin{array}{c}\text { Clarification } \\
\text { Requests }\end{array}$ & $\begin{array}{c}\text { Confirmation } \\
\text { Checks }\end{array}$ & $\begin{array}{c}\text { Comprehension } \\
\text { Checks }\end{array}$ & Total \\
\hline S1 & 1 & 1 & 0 & 2 \\
S2 & 1 & 1 & 0 & 2 \\
S3 & 1 & 1 & 0 & 2 \\
S4 & 2 & 2 & 0 & 4 \\
S5 & 1 & 3 & 0 & 4 \\
S6 & 5 & 4 & 0 & 9 \\
S7 & 1 & 1 & 0 & 2 \\
S8 & 1 & 0 & 0 & 1 \\
S9 & 2 & 1 & 0 & 3 \\
S10 & 0 & 1 & 0 & 1 \\
S11 & 2 & 0 & 0 & 2 \\
S12 & 0 & 1 & 0 & 1 \\
\hline Total & 17 & 16 & 0 & 33 \\
\hline
\end{tabular}

Table 4 shows the correlation between the subjects' use of interaction modifications (from both teacher-fronted and small group or pair work) and increases in test scores. The correlation coefficients returned for the Michigan test were not statistically significant, whereas the correlation coefficients for the CELT test were significant at the 0.01 level. 
Table 4

Subjects' Interaction Modifications - Increase in Test Score Correlation

\begin{tabular}{lcc}
\hline Test & Pearson & Spearman \\
\hline Michigan & -0.08077 & -0.29474 \\
& --- & -- \\
CELT & 0.790697 & 0.758568 \\
& $\mathrm{p}<0.002$ & $\mathrm{p}<0.004$ \\
\hline
\end{tabular}

To determine if the use of interaction modifications that 'stretch' the learners have a greater positive correlation with increase in English proficiency, as measured by increase in test scores, a weighted scale was used. As mentioned in chapter two, some researchers believe that interaction modifications that 'stretch' learners, by forcing them to use or modify their IL rules to produce output, may facilitate their L2 acquisition. Spada and Frohlich (1995) also mentions assigning weighted values to categories of interest in order to rank classes on their 'comunicativeness'. The weighted scale took the frequencies for each of the interaction modifications used by the individual subjects and assigned a value of ten for each use of a clarification request, five for each confirmation check, and one for each comprehension check. For example, a subject who used one confirmation check and three clarification requests would receive a weighted score of $1(5)+3(10)=35$. It should be noted that the values assigned to each of the interaction modifications are arbitrary. The size of the numbers chosen will of course affect the difference in amount of correlation. 
However, this amount of correlation is not of interest to the present discussion. The main point of interest is the direction of difference in the correlations. That is, the researcher is investigating whether trends can be found for the subjects' use of specific interaction modifications and increase in language proficiency. Therefore, the arbitrary nature of the weighting values assigned is not a consideration in this discussion. Table 5 shows the correlation between the weighted scale and increase in test scores.

Table 5

Weighted Interaction Modifications - Increase in Test Score Correlation

\begin{tabular}{lcc}
\hline Test & Pearson & Spearman \\
\hline Michigan & -0.1125 & -0.30444 \\
& --- & - \\
CELT & 0.734052 & 0.745099 \\
& $\mathrm{p}<0.007$ & $\mathrm{p}<0.005$ \\
\hline
\end{tabular}

Once the correlation results for the weighted scale were compared with those for the standard frequencies, it was noted that there was a slightly lower correlation between the weighted scale and increase in CELT test scores. This seemed counter-intuitive to the researcher. It would seem that, according to the current literature, learners who are testing and reformulating their IL rules, as evidenced by the use of interaction modifications that 'stretch' them to do so, would show a greater increase in test scores than those subjects who are not. Therefore, the weighted scale was adjusted to give more weight to confirmation checks than clarification requests. After reconsidering the literature, it became clear to the 
researcher that while a clarification request can be as simple as "What?", a confirmation check involves at least a partial repetition of the preceding utterance. Thus, the revised weighted scale assigned a value of ten for each confirmation check, five for each clarification request, and one for each comprehension check. Modifying the previous example of a subject who used one confirmation check and three clarification requests, the revised weighted scale would return a weighted score of $1(10)+3(5)=25$. Table 6 shows the correlation between the revised weighted scale and increase in test scores. As can be seen by comparing tables 4 and 6 , the correlation between the revised weighted scale and increase in CELT test scores is slightly larger than that for the standard frequencies of interaction modifications. However, the correlation coefficient for the Michigan test remains statistically insignificant.

Table 6

Revised Weighted Interaction Modifications - Increase in Test Score Correlation

\begin{tabular}{lcc}
\hline Test & Pearson & Spearman \\
\hline Michigan & -0.1125 & -0.30444 \\
& -- & $\ldots$ \\
CELT & .827273 & 0.755977 \\
& $p<0.001$ & $p<0.004$ \\
\hline
\end{tabular}

Subject Response to Interaction Modifications

Table 7 shows the frequencies and total number of each type of response to clarification requests used by the subjects. The total number of 
responses to clarification requests ranged from three single word responses to fourteen reformulations.

Table 7

Subjects' Responses to Clarification Requests

\begin{tabular}{ccccc}
\hline Response & $\begin{array}{c}\text { Single } \\
\text { Word }\end{array}$ & $\begin{array}{c}\text { Whole or Partial } \\
\text { Repetition }\end{array}$ & Reformulation & Total \\
\hline Subjects & 1 & 1 & 0 & 2 \\
S1 & 0 & 0 & 0 & 0 \\
S3 & 0 & 2 & 0 & 2 \\
S4 & 0 & 0 & 0 & 0 \\
S5 & 0 & 0 & 3 & 3 \\
S6 & 0 & 1 & 1 & 2 \\
S7 & 0 & 0 & 3 & 3 \\
S8 & 0 & 0 & 0 & 0 \\
S9 & 0 & 1 & 2 & 3 \\
S10 & 2 & 1 & 1 & 4 \\
S11 & 0 & 0 & 0 & 0 \\
S12 & 0 & 2 & 4 & 6 \\
\hline Total & 3 & 8 & 14 & 25 \\
\hline
\end{tabular}

Table 8 shows the frequencies and total number of each type of response to confirmation checks used by the subjects. Table 8 also shows combined totals for responses to both clarification requests and confirmation checks for each subject. Subjects used reformulations more than three times as often (3.25) when responding to a clarification request than to a confirmation check. Subjects used whole or partial repetitions two times more often when responding to a clarification request than to a confirmation check. Subjects used single word responses four times as often when responding to confirmation checks than to clarification requests. 
Since no comprehension checks by the instructor were recorded, there are no data available for analysis of students' responses to comprehension checks.

Table 8

Subjects' Responses to Confirmation Checks

\begin{tabular}{ccccc}
\hline Response & Single Word & $\begin{array}{c}\text { Whole or Partial } \\
\text { Repetition }\end{array}$ & Reformulation & Total \\
Subjects & & 0 & 0 & $4(6)$ \\
S1 & 4 & 0 & 0 & $0(0)$ \\
S2 & 0 & 1 & 0 & $4(6)$ \\
S3 & 3 & 1 & 1 & $2(2)$ \\
S4 & 0 & 0 & 0 & $1(4)$ \\
S5 & 1 & 1 & 0 & $1(3)$ \\
S6 & 0 & 0 & 1 & $1(4)$ \\
S7 & 0 & 1 & 0 & $1(1)$ \\
S8 & 0 & 0 & 0 & $1(4)$ \\
S9 & 1 & 0 & 0 & $1(5)$ \\
S10 & 1 & 0 & 0 & $0(0)$ \\
S11 & 0 & 0 & 2 & $4(10)$ \\
S12 & 2 & 4 & 4 & $20(45)$ \\
\hline \multicolumn{2}{r}{ Total } & 12 & Noter Combined totals for responses to clarification requests and \\
Confirmation checks for each subject are in parenthesis. &
\end{tabular}

Table 9 shows the correlation between subjects' responses to interaction modifications and increases in test scores. The correlation coefficients for both the Michigan test and CELT test are not statistically significant. 
Table 9

Responses to Interaction Modifications - Increase in Test Score Correlation

\begin{tabular}{lcc}
\hline Test & Pearson & Spearman \\
\hline Michigan & -0.13038 & -0.08319 \\
& --- & -- \\
CELT & 0.139713 & 0.096257 \\
& $\mathrm{p}<0.665$ & $\mathrm{p}<0.766$ \\
\hline
\end{tabular}

To analyze whether responses that required subjects to produce output based on their IL rules were correlated with increase in language proficiency, a weighted scale was used. As mentioned earlier, the current literature suggests that learners who reply with one-word answers are not being pushed to modify their IL rules as much as those learners who respond with longer utterances. For example, while one-word responses may be appropriate at times, they do not require as much reliance on IL rules as reformulations. Thus, the weighted scale is intended to reflect, to some extent, the cognitive requirements of a response. The weighted scale assigned a value of ten for each reformulation, five for each whole or partial repetition, and one for each single word response. Consequently, a subject who responded to interaction modifications one time with a single word, once with a whole or partial repetition, and twice with a reformulation would receive a weighted score of $1(1)+1(5)+2(10)=26$. Table 10 shows the correlation between the weighted scale and increase in test scores. There 
is an increased correlation for the CELT test data. However, the Spearman correlation coefficient of $0.470803(p<0.122)$ is not statistically significant. Table 10

Weighted Responses to Interaction Modifications - Increase in Test Scores Correlation

\begin{tabular}{lcc}
\hline Test & Pearson & Spearman \\
\hline Michigan & -0.06999 & -0.11072 \\
& --- & -- \\
CELT & 0.259609 & 0.470803 \\
& $p<0.415$ & $p<0.122$ \\
\hline
\end{tabular}

Figure 1 shows a comparison between the subjects' use of interaction modifications, responses, and increase in Michigan test and CELT test scores. 


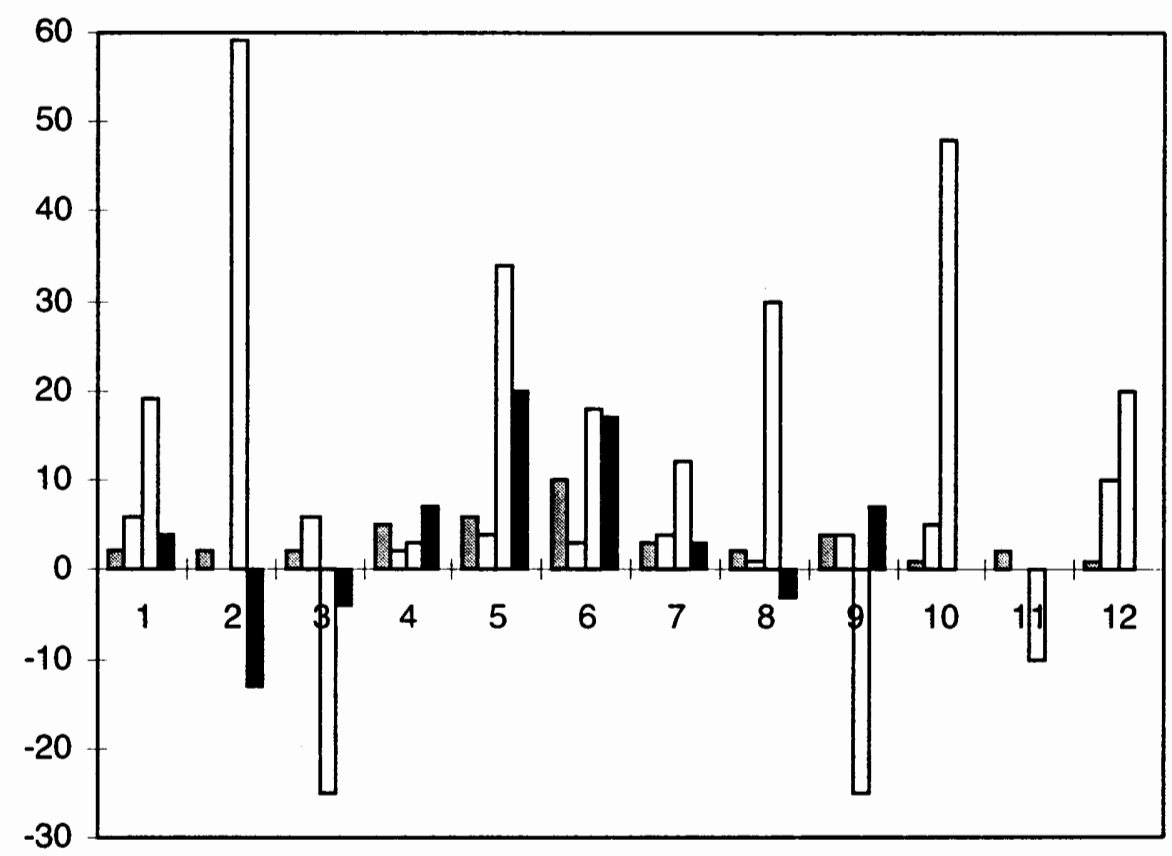

Subjects

圆 Interaction Modifications $\square$ Responses $\square$ Michigan Test $\square$ CELT

Figure 1. Comparison of subjects' interaction and increase in test scores.

Subject 'Interactiveness'

To analyze the subjects' overall 'interactiveness', the frequencies of the subjects' use of interaction modifications and responses to interaction modifications were combined. This was done in order to give a larger 'interactiveness' score to subjects who use both interaction modifications and responses that require them to rely more on their IL rules. Table 11 shows the correlation between the subjects' overall interactiveness and 
increase in test scores. The Michigan test had no statistically significant correlation with the subjects' overall interactiveness. However, the Spearman correlation returned a coefficient of $0.604279(P<0.37)$ for the CELT test.

Table 11

Overall 'Interactiveness' - Increase in Test Score Correlation

\begin{tabular}{lcc}
\hline Test & Pearson & Spearman \\
\hline Michigan & -0.16925 & -0.16992 \\
& -- & -- \\
CELT & 0.713141 & 0.604279 \\
& $\mathrm{p}<0.009$ & $\mathrm{p}<0.037$ \\
\hline
\end{tabular}

Table 12 shows the correlation between the combined weighted scales and increases in test scores. Again, the Michigan test showed no statistically significant correlation with the subjects' weighted overall interactiveness. However, the weighting increased the Spearman correlation coefficient, $0.65726(p<0.020)$, returned for the CELT test.

Table 12

Weighted 'Interactiveness' - Increase in Test Score Correlation

\begin{tabular}{lcc}
\hline Test & Pearson & Spearman \\
\hline Michigan & -0.1349 & -0.21053 \\
& --- & -- \\
CELT & 0.735759 & 0.65726 \\
& $\mathrm{p}<0.006$ & $\mathrm{p}<0.020$ \\
\hline
\end{tabular}


Table 13 shows the correlation between the combined revised weighted interaction modification scale and weighted responses to interaction modifications, and increase in test scores.

Table 13

Revised Weighted 'Interactiveness' - Increase in Test Score Correlation

\begin{tabular}{lcc}
\hline Test & Pearson & Spearman \\
\hline Michigan & -0.1349 & -0.21053 \\
&.-- &.- \\
CELT & 0.742041 & 0.632526 \\
& $\mathrm{p}<0.006$ & $\mathrm{p}<0.027$ \\
\hline
\end{tabular}

The results of the data analysis will be discussed in chapter five. 
harmonious integration (wa) of group members" (p. 49). Since wa (harmony within the group) is a key value in Japanese society, Japanese people tend to think and behave as a group. The emphasis on the group often causes Japanese people to refrain from standing up for themselves and to follow the group instead (Honna \& Hoffer, 1989). The value placed on collectivism, in contrast to individualism, relates to the Japanese tendency for non-confrontation, group consensus and limiting the expression of personal thoughts. These behaviors, revealing the effects of wa, will be examined individually.

Since confrontation is seen as a threat to group harmony, Japanese tend to practice self-restraint in order to try to minimize or avoid its disruptive effects (Watanabe, 1990). Brown and Levinson (1987) state that confrontation is a Face Threatening Act (FTA) in Japan. The concept of face is very important in maintaining group harmony in the Japanese culture. Hirokawa (1987) defines loss of face as "The loss of self-respect and dignity resulting from public humiliation and embarrassment" (p. 139). Therefore, Japanese avoid confrontation in order to avoid or prevent the 'loss of face' and disruption of group harmony. Other tactics used in avoiding loss of face include indirect, ambiguous expressions and silence (Nakane, 1977; Ramsey, 1985). These tactics will be discussed in later sections. 
The individual's sense of group is very strong in Japan (Taylor, 1983). The Japanese have a very strong sense of who is on the inside (in-group), or uchi, and who is on the outside (out-group), or soto. The in-group defines a boundary, and hierarchy within the group is a guide for proper verbal and non-verbal behavior. For example, in linguistic behavior forms of address vary depending on whether the interlocutors are members of the same ingroup. Depending on the relationships, the forms of address used (either direct or distal, formal or informal) are completely different. When a subordinate is speaking to a superior in his or her in-group, honorific titles (e.g., -san, -butyoo, -kakarichyoo) are attached to the end of the superiors' family name. However, when the subordinate is referring to this same superior to a member of the out-group, these titles are dropped. Honna and Hoffer (1989) state that "Conformism fosters a great sense of oneness shared by all the members in the same group" (p. 123). A member who deviates from the group norms or disturbs the group consensus may take the risk of being excluded from the group. There is a Japanese saying which expresses this point:

Deru kui wa utareru.

The post/stake that sticks out will be pounded down. Members of a group share in the group's capacity for success and its refusal to blame individuals within the group. Therefore, loyalty to the group and a willingness to submit to its demands are key virtues in Japanese society. 
This way of viewing relationships through the perspective of the group creates a distinctive style of decision making in Japan known as consensus decision. Watanabe (1990) found that, for the Japanese participants in her study, the goal of group discussions was to reach unanimous conclusion with no one being left feeling frustrated or dissatisfied. Therefore, everyone in the group must be considered. However, personal objections or doubts are avoided in order to preserve group harmony. This has been the case in the traditional household (uchi), the symbol of the group in Japan. Nakane (1977) notes that:

In the ideal traditional household in Japan ... opinions of the members of the household should always be held unanimously regardless of the issue ... an expression of a contradictory opinion to that of the head was considered a sign of misbehavior, disturbing the harmony of the group order. ( $p$. 13)

The Japanese place a high value on sensitivity rather than on verbal skill. In Japan words are somewhat distrusted and seen as less reliable guides to a complex and elusive reality. That is, words are a means, but not the only means, of communication. Therefore, in consideration of the virtue of group harmony, the free voicing of personal opinions is avoided. Okabe (1987) comments that "To express the speaker's demand, rejection, assertion, or criticism to the listener directly or straightforwardly is often regarded as impoliteness or as bad manners in human relationships in Japanese society" (p. 135). Thus, individuals withhold their personal 
opinions in order to preserve the harmonious atmosphere of the group and also to prevent loss of face, and thereby disruption of the group harmony, should their opinion be at odds with the rest of the group.

Japanese are also known for their indirect style of speech. Features of this Japanese communication style will be more fully examined in the following sections.

\section{Taciturnity}

Tsujimura (1987) defines taciturnity as "the reluctance to talk a lot or the use of indirect expression rather than direct expression" (p.116). He further notes that "When taciturnity is carried to extremes, communication occurs when nothing is said" (p. 117). Tsujimura explains that the Japanese tendency toward taciturnity is due to: (1) the relative racial, cultural and linguistic homogeneity of the Japanese, and (2) the effects of the feudal era and the restraints on communication that it placed on the Japanese people for over one hundred years. Thus, due to the emphasis on taciturnity and non-verbal communication, the nature of the roles of speaker and listener in Japan is different from that in other cultures. These differences, which relate to the responsibility of the speaker and listener, will be discussed in the next section.

Hall $(1976,1984)$ states that Japan is a high-context culture. In a high-context culture such as Japan, most information tends to be in the 
physical context and internalized into the person. Therefore, people need not participate actively in verbal interaction. The following Japanese saying exemplifies this point:

Ichi o kiite, zyuu o siru.

Hearing one, s/he understands ten.

This ability to 'listen between the lines' and understand the speakers intentions and desires affects the responsibilities of the speaker and listener.

\section{Enryo}

In Japan, the speaker, depending on the listener and the communicative situation, simplifies and economizes messages rather than elaborating on them. Enryo (reserve or restraint) expresses one of the most important Japanese cultural values (Wierzbick, 1991). Lebra (1976) comments:

Pressure for conformity often results in a type of self-restraint called enryo, refraining from expressing disagreement with whatever appears to be the majority's opinion. (p. 29)

One way to express enryo is to avoid giving opinions, in particular, dissenting opinions. Enryo concerns not only people's personal opinions, but also their desires, their preferences, their wishes. It calls for a selfeffacement that prevents people from saying clearly not only what they think, but also what they want. Enryo is the product of the suppression of individuality under the pressure of group solidarity and conformity. It can 
also be thought of as the psychological 'exit', through which encoded messages are sent. Thus, the person of good enryo considers the active, exaggerated expression of ideas and feelings to be degrading and foreign (Ishii \& Bruneau, 1994). Therefore, ideas and feelings that might hurt the listener(s) or damage the general atmosphere when expressed are carefully sent back for re-examination in an internal self-feedback process. Only those ideas judged safe and vague are allowed to be sent out through this screening filter. On the receiving end, the Japanese listener uses sasshi.

\section{$\underline{\text { Sasshi }}$}

To make communicative interaction possible in the high-context situation, the Japanese listener is expected to possess acute sensitivity. When receiving a message, the restricted and vague information is appropriately developed according to the listener's ability, called sasshi, to discern the other person's meaning or needs. Ishii and Bruneau (1994) note that in Japanese interpersonal relations, a person of good sasshi, who is good at mind-reading or perceiving intuitively people's ideas and feelings, is highly appreciated. The roles of speaker and listener in Japanese culture help to maintain the sense of group harmony by allowing disagreement or personal needs to be expressed indirectly and ambiguously, rather than overtly. Thus, the sense of enryo-sasshi is of utmost importance in highcontext Japanese interpersonal relations. 
Another difference in Japanese communication is the use and value placed on silence.

\section{Silence}

The general attitude of Japanese people toward language and verbalization is that "fewer words, supported by the aesthetics of vagueness, are better than more words" (Ishii \& Bruneau, 1994, p.248). In Japanese society, silence and silences are generally considered to have a positive, meaningful value. Thus, they are socio-culturally accepted to a much higher degree in Japan than in countries like the U.S. Nakane (1977) notes that Japanese prefer to be silent rather than utter words such as 'no' or 'I disagree' for fear of disrupting the harmony of the group. Therefore, one uses silence in order to preclude the embarrassment caused by such a face threatening act, and save not only one's own face but that of the other person.

The previous discussion has shown that the Japanese orientation towards non-confrontation and non-dialectical interpersonal relations, as well as their nonverbal, intuitive communication practices, is based on the socio-cultural importance placed on the group and maintaining group harmony. All these socio-cultural values affect how Japanese students interact with their interlocutors. In the following section these effects will be discussed. 


\section{Effects on Interaction}

Barnlund (1975) states that "The communicative consequences of the cultural encouragement of 'reserve' and 'caution' among Japanese may produce an other-oriented person, who is highly sensitive and receptive to meanings in others" (p. 160). However, these cultural values are not limited to interaction with other Japanese within Japanese society. Ishii, Kloph, and Cambra (1984) found that Japanese students were less dominant, less inclined to initiate and maintain conversations, less apt to speak frequently and long, less inclined to talk, and less fluent than U.S. students. Other researchers (see, for example, Reischauer, 1977; Watanabe, 1990) have also found that, despite lengthy stays in the U.S., Japanese students interact differently in group discussions. Thus, it is difficult for Japanese students to ask questions freely, state their opinion, argue, and criticize as much as American students do. Besides the socio-cultural values examined earlier, this difference may also be due to differences in the Japanese school system.

The Japanese system of education reflects Confucian ideas and values, i.e., respect for learning and educators who devote their lives to learning. According to Beauchamp (1992):

Education arrangements of every society are a natural outgrowth of that society's historical development, cultural elements, and economic and political realities. (p.7) 


\section{CHAPTER V}

\section{DISCUSSION}

This case study describes student-student and student-teacher interactions, with a focus on interaction modifications for the purpose of negotiating meaning. In the following discussion, the results of the data analysis from chapter four will be used in answering the six research questions from chapter one. This study's limitations, application to the field of second language acquisition, and suggestions for further research will also be presented.

\section{Discussion}

Research question (1) asks "What interaction modifications do Japanese ESL learners use in teacher-fronted classes?" The data from table 2 show that the twelve subjects, as a whole, did not use many interaction modifications in the teacher-fronted classes observed. However, individual differences are apparent. In the classes observed, the subjects used a total of four clarification requests, three confirmation checks, and no comprehension checks. These clarification requests and confirmation checks were regarding the meaning of directions being given by the instructor about commands used for computer functions.

An example from the corpus will help to illustrate the subjects' use of clarification requests in teacher-fronted classes: 
1. T: Type Pnews at the shell prompt.

2. S8: Type what?

3. T: P-N-E-W-S.

4. S8: OK.

In line one, the instructor is telling the students how to get to the news reader on the Odin system. Subject S8, in line two, responds with a two word clarification request. This clarification request is an example of an uninverted question with rising intonation. The instructor responds by spelling out the command, and the subject then signals her comprehension.

The discourse below is an example of a confirmation check used by a subject in a teacher-fronted class:

1. T: Maybe you can type a little more. First type ' $Y$ '.

2. S9: Type 'why"?

3. T: No, you can just enter the letter ' $Y$ ' (pointing to keyboard) and push 'return'. ...

In line one, the instructor is prompting subject $\$ 9$ to type more in her e-mail message. He instructs her to first "type $Y$ ", but she misunderstands the meaning of "Y" ( $Y=$ yes, a response to a prompt from the Odin server). Subject S9 responds with a confirmation check; a repetition of what she perceived to be part of the preceding utterance. The instructor then 
responds by explicitly telling subject $S 9$ to enter the letter ' $Y$ ', while indicating the Y-key on the keyboard. Both of the examples from the interaction modifications used in the teacher-fronted classes are quite simple. Whether this is due to the type of class, or the subject's language skills can not be determined at this point. The discussion of the complexity of the interaction modifications used by the subjects will be returned to in the discussion of interaction modification in small group and pair work situations.

The minimal amount of interaction modifications used by the subjects in the teacher-fronted classes is not surprising when the results from studies mentioned in chapter one are considered. The present study's findings agree with those by Pica and Long (1986) and Long and Sato (1983), who found few interaction modifications, by students or teachers, in teacherfronted classrooms. Teachers' use of preplanned lessons and their experience with learner production are two factors limiting the amount of negotiation that can occur in the classroom. Often instructors understand everything learners say to them and pitch their $L 2$ input at a level of complete comprehensibility.

The absence of comprehension checks by the subjects in teacherfronted classes is not unusual. Because there is a one-way flow of information from the teacher to the students, the students only have an opportunity to receive, rather than disseminate, information. Since the 
students are not contributing any new information to the class or to the teacher, it is not necessary for them to check the listeners' comprehension.

Cultural influences may also provide an explanation for the amount of interaction modifications used by the subjects in teacher-fronted classes. The lack of interaction modifications by the subjects may be due to their previous scholastic experience. Since Japanese classrooms are traditionally teacher centered, and open class discussion is not often used as a teaching method, students have little experience in asking questions, expressing opinions, or negotiating meaning. Thus, the subjects do not engage in interaction modifications simply because they do not know how. Also, the subjects' minimal use of interaction modifications may be a result of the limitations that the hierarchy that exists within the classroom imposes on classroom interaction. As noted in the literature review, the importance of hierarchy and group harmony is apparent everywhere in Japanese society. These features account for the lack of learner-centered instruction and the opposition to evaluation of teachers by students. Clarification requests or confirmation checks may be viewed as violating the principles of hierarchy because they question the teacher's authority by implying that the teacher has not been clear or thorough. Since direct confrontation should be avoided, students may refrain from asking questions or choose to ask the teacher questions after class. Also, by asking a question, students put themselves at risk of losing face because they may be seen by the group as 
making a mistake in comprehension, or as having poor verbal or non-verbal communication skills. Initiating interaction by asking a question may also involve the student in extended discourse with the teacher. This discourse may lead to further interaction modifications with their inherent potential for loss of face by the student and disruption of group harmony of the class.

The data suggest that Japanese ESL learners use few interaction modifications in teacher-fronted classes. Also, the interaction modifications that they do use are syntactically simple. However, it cannot be determined from the data whether these findings are due to the students themselves, or the style of the class.

Research question (2) asks "What interaction modifications do Japanese ESL learners use in pair-work or small-group situations?" The data from table 3 show that all the students used more clarification requests and confirmation checks in small group or pair work situations than in the teacher-fronted classes. Overall, the subjects used only seven interaction modifications in the teacher-fronted classes while they used thirty-three interaction modifications in small group and pair work situations. One possible explanation for the increase in interaction modifications may be the subjects' difficulty in comprehending other non-native speakers. That is, the subjects' clarification requests and confirmation checks seem to be triggered by a failure to comprehend the meaning of lexical items used in conversation by their interlocutors. However, in the teacher-fronted classes, 
the instructors' directions were more often the cause of the few interaction modifications used by the subjects. An example from the corpora of the subjects' use of clarification requests and confirmation checks in small group or pair work follows. In this sample, tThe students are working in small groups to prepare interview questions about peoples' use of the internet:

1. S12: (to S6) What do you think the merit of the internet?

2. S6: Merit? What does that mean?

3. S12: ... merit, demerit ... (pausing)

4. S6: Positive and negative point?

5. S12: Yes. Shopping ...

6. S6: Oh. What do you think are the positive point of the internet?

In line two, subject S6 asks for clarification of the lexical item 'merit'. She repeats the unknown word, and then uses a wh- question to elicit clarification from subject $\mathrm{S} 12$. Subject $\mathrm{S} 12$ attempts to explain her intended meaning by giving the antonym, demerit, as an example in line three. Subject $\mathrm{S} 6$ follows up with a confirmation check by paraphrasing subject S12's explanation to make sure she (S6) has understood the intended meaning in line four. Subject $\mathrm{S} 12$ responds positively to the confirmation check, and continues her turn with an elaboration attempt. 
This example illustrates the difference in complexity of the discourse produced through interaction modifications for the purpose of negotiation of meaning in teacher-fronted classes, and small group or pair work situations. As a whole, the syntactic structure is more complex, and the phrases longer in small group interactions. One possible explanation for the difference is that in teacher-fronted classes the instructor, a native speaker, did not cause as many communication breakdowns by his output, and was able to prevent or repair breakdowns caused by his interlocutors' output. Thus, with his advantage in target language skills, he was able to modify his output to help the learners more easily obtain comprehensible input. In small group or pair work, however, the subjects must rely on their own and their interlocutor's language proficiency to prevent communication breakdowns from occurring and repair them when they do occur. However, their understandably lower target language proficiency may cause more frequent breakdowns in communication and make their attempts at preventing breakdowns from occurring less successful. When a breakdown in communication does occur, the interlocutors' lower language skills may also require them to work longer and harder to regain mutual comprehension.

Another possible explanation has to do with the influence of culture. As mentioned in chapter two, some learners signal comprehension even though none has occurred. The Japanese subjects may indicate to the instructor that they understand in order to avoid confrontation and maintain 
group harmony. When interacting within their own group, with students who have the same status, the Japanese students may feel more comfortable in persisting in negotiating for meaning.

As in the teacher-fronted classes, the subjects did not use any comprehension checks. Initially, this result of the data analysis seemed a little unusual. The explanation for the subjects' lack of use of comprehension checks in teacher-fronted classes was based on the oneway flow of information inherent in that context. In small group or pair work situations, however, there presumably should be a two way exchange of information. Thus, the subjects should be in a position to check their interlocutors' comprehension of what they have just said. Again, the role of cultural influences may offer an explanation. As noted in chapter two, the Japanese subjects may simply lack experience in checking comprehension. In Japan, checking comprehension is role-related. Japanese teachers typically use comprehension checks, but students do not. The subjects may refrain from checking their interlocutors' comprehension because to do so would seem to imply that the other person(s) is of poor sasshi. That is, their ability to discern the other person's meaning or needs, is weak. This would be a direct confrontation and cause disruption of the group harmony. Thus, the subjects' enryo (reserve or restraint) results in their withholding the comprehension check. In addition, if a student was to assume the role of teacher and check another student's comprehension, that student may be 
perceived as being arrogant by the other students, once again disrupting group harmony.

Without any empirical evidence of the subjects' intentions or reasons for not using comprehension checks, a definite conclusion regarding their actions cannot be reached.

A final possible explanation, one that does have empirical support in other studies, is that comprehension checks are not used as frequently as the other interaction modifications in NS-NS and NS-NNS interactions.

In summary, Japanese ESL learners use clarification requests and confirmation checks equally in small group or pair work situations.

Research question (3) asks "Is an increased use of interaction modifications positively correlated with an increase in English proficiency as measured by increase in Michigan test scores?" The data from table 4 show the results for both the Pearson and Spearman correlations. No correlation was found between increases in Michigan Test scores and use of interaction modifications. However, both correlations returned a very high correlation coefficient, with a corresponding high confidence level, between use of interaction modifications and increases in CELT test scores. The more conservative Spearman correlation returned a correlation coefficient of $0.759,(p<0.004)$. A possible explanation for this unexpected result is based on what the respective tests measure. The Michigan Test is a test of grammar and reading comprehension, while the CELT is a listening 
comprehension test. The studies mentioned in chapter two only found evidence of interaction modifications facilitating listening comprehension on task based instructions. No studies found empirical support for interaction modifications facilitating the acquisition of syntactic structures. Thus, it seems natural that the use of interaction modifications is more closely correlated with increase in listening comprehension, as measured by the CELT.

Thus, the answer to research question (3) is yes. There is a statistically significant correlation between use of interaction modifications and increase in English proficiency as measured by increases in CELT test scores. The use of interaction modifications by the subjects appears to be one factor facilitating their increase in language proficiency.

Research question (4) asks "Does the amount of use of some interaction modifications have a greater positive correlation with increase in English proficiency, as measured by increase in Michigan test scores, than the amount of use of other interaction modifications?" The data from table 5 and table 6 show the weighted scales used to determine if the use of specific interaction modifications is more positively correlated with increase in test scores. As noted previously, there was no correlation found between the weighted scales of interaction modifications and increase in the Michigan test scores. However, a strong positive correlation was found between the weighted interaction modifications and increase in CELT test 
scores. Using the results from the more conservative Spearman correlation, the scale assigning greater weight to clarification requests returned a correlation coefficient of $0.745(p<0.005)$. The scale that assigned a greater weight to confirmation checks returned a correlation coefficient of $0.756(p<0.004)$. These results are interesting because they imply that use of confirmation checks may facilitate acquisition by 'stretching' the learner to produce output more than clarification requests do. This may be because clarification requests can be as simple as 'What?', or some other formulaic expression, while confirmation checks require at least a partial repetition of what was perceived as the preceding utterance. Thus, the learner may have to rely on her IL rules more to produce a confirmation check in comparison to a clarification request. It must be noted that the small difference between the Spearman correlation coefficients for the two weighted interaction modification scales is not statistically significant. Also, with the small amount of data the results are not reliable except to note general trends. It should also be noted that neither weighted scale returned a correlation coefficient as large as the simple frequency correlation done for Table 4. Thus, based on the data from this study, it can not be claimed that the use of any one interaction modification facilitates $L 2$ acquisition more than any other. All interaction modifications appear to benefit learners equally, especially with respect to listening comprehension. 
Research question (5) asks "How do Japanese ESL learners respond to clarification requests, confirmation checks, and comprehension checks (e.g., single word, full or partial repetition, or reformulation)?" The data from table 7 show the subjects' responses to clarification requests. Most of the subjects responded to clarification requests with either reformulations (14) or repetitions (8) of their previous utterances. The following example from the corpus shows the subjects' responses to clarification requests:

1. S10: Strong points are getting a lot of information ... and weak points are getting bad sight and taking a lot of time.

2. T: What was the first part for the weak points?

3. S10: Getting bad sights.

4. T: Getting bad sights? What do you mean by bad sights?

5. S10: Having bad eyes.

6. T: Oh, bad sight, so it's bad for your eyes?

7. S10: Yes.

In line two the instructor asks for clarification of part of the subject's preceding utterance. Subject $S 10$ responds with a partial repetition of the relevant point in line three. The instructor follows up with another, more specific, clarification request in line four. In line five, subject $\mathrm{S} 10$ uses a reformulation in response to the clarification request. This results in the 
instructor checking his comprehension with a confirmation check in line six. In line seven, the subject responds with a one word answer.

It is noteworthy that the responses to the clarification requests are significantly longer and syntactically more complex than the response to the confirmation check. Although the partial repetition in response to the first clarification request in line two might not be too cognitively demanding, it still requires use of the subjects' IL rules in its production. The reformulation, in line five, requires the subject to use new lexical items and also may draw her attention to her IL rules in order to check for structural problems that may be causing the miscommunication. These findings agree with those reviewed in chapter two which state that clarification requests to the learner may 'stretch' them more than confirmation checks. It should be noted that two subjects, $\mathrm{S} 1$ and $\mathrm{S10}$, responded to clarification requests with single word answers. These responses do not seem to be appropriate for a clarification request. It may be that the subjects misunderstood the request or were unable to formulate any other response.

The data from table 8 show the subjects' responses to confirmation checks. The subjects used many more single word responses (12) than either whole or partial repetition (4) or reformulations (4). This is not unusual considering the previous discussion about confirmation checks. Since the interlocutor solves the communication problem for the speaker, a 
simple one word response is most often appropriate. The following examples show the subjects' responses to confirmation checks:

1. S1: Do you have your computer in your house?

2. T: Where do you have your computer?

3. S1: No.

4. T: Do you have your own computer?

5. S1: Yes.

6. S6: From about four years ago, to about two years ago.

7. T: So, the longest time was from about two years ago?

8. S6: Four years ago.

9. T: Four years ago.

The instructor, in line two, confirms his comprehension of subject S1's previous utterance with a reformulation. Subject $\mathrm{S} 1$ responds with a one word answer in line three. The instructor follows up with another confirmation check in line four. This time, he has corrected the communication breakdown so Subject $\mathrm{S} 1$ responds with a one word answer, yes. This portion of discourse is a good example of the way native speakers often solve communication problems for non-native speakers. This method, while being expedient, does not require non-native speakers to produce output based on their IL rules. As noted in chapter two, this 
output may be important in learners modifying their IL rules and moving towards more target like usage.

In line seven of the example, the instructor uses a confirmation check, triggered by the subject's strange wording in the previous utterance. In line eight the subject, S6, responds with a partial repetition of her previous utterance. This is interesting because it includes the pragmatic meaning of 'no'. Whether the subject (S6) knew she was doing this or not is not clear from the transcript. However, it appears that she is beginning to develop some understanding of implied meaning.

It should be noted that two subjects, $\mathrm{S} 2$ and $\mathrm{S} 11$, had no responses to either clarification requests or confirmation checks. This may be due to problems with tape quality during transcription. However, with respect to subject S2, her personality may also offer an explanation. From the classroom observations and personal contact, the researcher noted that subject $\mathrm{S} 2$ is very shy and quiet. For example, the researcher noted that during small group or pair work subject $\mathrm{S} 2$ did not interact with the other subjects. She also used nonverbal communication (nodding her head, etc.) when the instructor attempted to engage her in interaction. Therefore, she did not take part in any extended dialogues, and hence, she did not experience a breakdown in communication with her interlocutors that would require discourse modifications to repair. 
As noted in chapter four, no comprehension checks by the instructor were recorded. Therefore, no data on the subjects' responses to comprehension checks were available. However, simply because comprehension checks by the instructor were not recorded does not mean that none were used. The poor quality of the tape may have caused the researcher to miss comprehension checks by the instructor. Also, the instructor, at times, used display questions (questions whose answer is already known by the speaker) to check comprehension. These display questions resulted in partial or full choral responses by the class. Below is an example of a display question used to check the subjects' comprehension. The instructor has just finished covering how to use the news reader on the Odin system.

1. T: What's the name of the news reader that we use at ()?

2. Ss: Tin. (choral response)

3. T: T-I-N, tin, right. ... (continues with instructions for posting a message to a newsgroup)

In line one, the instructor uses a display question to check the subjects' comprehension of the previous material. In line two the subjects respond chorally with the correct, single word, answer. While this example is a display question, the response is also typical of comprehension checks. That is, responses to comprehension checks are most frequently a one 
word or formulaic response. Just as display questions have been shown to result in shorter responses than referential questions (questions whose answer is not already known by the speaker), comprehension checks elicit shorter responses than clarification requests. Since the researcher could not pick out individual subject's in the choral responses, while listening to the tapes, no responses could be coded.

In answer to research question (5), Japanese ESL learners respond to clarification requests predominantly through reformulations, followed by whole or partial repetition. Japanese ESL learners respond to confirmation checks mainly through single word answers, followed distantly by repetitions and reformulations. These findings are similar to those in several studies mentioned in chapter two which discuss how interaction modifications might 'stretch' learners to modify their IL rules when producing output. Since the interlocutor generally solves the communication problem for the speaker, confirmation checks do not 'stretch' learners as much as clarification requests.

Research question (6) asks " Is there a positive correlation between the manner in which Japanese ESL learners respond to interaction modifications (e.g., single word, full or partial repetition, or reformulation) and increase in English proficiency, as measured by increase in Michigan test scores?" Table 9 shows the correlation results for the subjects' responses to interaction modifications. There is no correlation with either 
the Michigan test or the CELT. This may be due to the relatively large number of responses given by subjects $S 3, S 10$, and $S 12$, all of whom showed little or no increase in test scores. If the opportunity to respond, to produce the target language based on IL rules, promotes language proficiency, then students who respond more would be expected to have a larger increase in test scores than those who do not. However, concerning these subjects, this does not appear to be the case. It may be that the subjects' low language proficiency triggered more interaction modifications, for the purpose of negotiation of meaning, by their interlocutors than subjects with higher language proficiency. Also, except for subject S12, the lower proficiency learners tended to use simple one word or partial repetition responses to interaction modifications. Thus, these responses would not require as much conscious attention to the subjects' IL rules to formulate as reformulations would.

To account for this, a weighted scale was used in the correlation tests. Table 10 shows the results for this correlation analysis. Although there is an increase in the correlation with CELT test scores, the level of the Spearman correlation coefficient, $0.470803(p<0.122)$, is not statistically significant. Thus, the study found no statistically significant correlation between the manner in which Japanese ESL learners respond to interaction modifications and language proficiency, as measured by increase in Michigan test or CELT test scores. 
The results of the correlation tests done for the subjects' overall 'interactiveness' are displayed in tables 11,12 , and 13. The unexpected results from the analysis done on the subjects' responses to interaction modifications skewed the combined correlation results. The literature reviewed lead the researcher to believe that learners who use reformulations or full repetitions when responding to clarification requests or comprehension checks would have a greater increase in test scores than those learners who respond with single word answers. That is, learners who produce output based on their IL rules will have a greater increase in English proficiency test scores than learners who do not. This is because the learners who attend to their IL rules may notice differences between the input they receive and the output they produce, and thus reformulate their IL rules to permit the structure of the input. However, the data does not support this view. Thus, the correlation coefficients returned by the Spearman test for the subjects' 'interactiveness' and increase in CELT test scores, although statistically significant, are lower than the correlation coefficients for the subjects' use of interaction modifications.

\section{Limitations}

This research is limited by the number of subjects, the quality of the audio-tapes, the tests used to measure the subjects' language proficiency, and the lack of input from the subjects about their reasons for observed classroom behavior. 
The small number of subjects makes it extremely difficult to come to any definitive conclusions regarding Japanese ESL students' use of interaction modifications. Also, the subject population may not be typical of Japanese learners as a whole. Even if they are typical of Japanese ESL learners, they might not represent Japanese EFL learners.

The poor quality of the audio-tapes made it very difficult for the researcher to isolate and transcribe individual subjects' utterances. Although field notes clarified some points, they could not completely compensate for the poor tape quality.

Measuring students' language proficiency is always a difficult task. The type of testing instrument used will inevitably influence the results to some extent. To measure the effect of learner use of interaction modifications on language proficiency, other instruments besides the Michigan test and CELT test need to be found.

Since the tape transcription took longer than expected (approximately six hours for every hour and fifty minute class), because of the poor tape quality, the subjects could not be questioned about their behavior in the individual interviews that were conducted. Therefore, only general information about class style preferences and views on classroom behavior could be elicited from the subjects during these interviews. Since these interviews did not yield any information that could help explain the subjects' 
use of interaction modifications, they were excluded from the results and discussion.

Also, although the COLT is a very valuable instrument for recording classroom behavior, it does take time and experience to become proficient in coding the various categories. When adapting it for special purposes, as was done in this study, researchers must be careful to maintain the integrity of the instrument. Further, there is some difficulty when recording small group or pair work situations. If the observer is only using one recording device, as was the case in this study, the discourse of the other subjects is lost while the observer is focusing on one group. This problem can be overcome by having additional observers and recording devices. However, this solution runs the risk of disrupting the class and affecting the data.

To improve this study, a larger sample of Japanese ESL students' uses of interaction modifications needs to be included. Also, non-Japanese ESL students need to be included in the study. If the class style and teaching methodology used were kept constant, this would allow a comparison of their use of interaction modifications with that of Japanese students to determine if Japanese students use fewer interaction modifications than the norm. In addition, further investigation into if and how interaction modifications facilitate second language acquisition is necessary for a complete explanation of the process. 
Suggestions for the improvement of audio-tape quality include using headphones at the time of recording in order to determine the quality of the taping. Use of headphones would also permit the researcher to use the sound mixer to isolate individual students. Most of the research done on interaction modifications has been in laboratory situations with one NS and one NNS being recorded studied at a time. While this is an ideal setting for obtaining clear recordings and controlling the structure of experiments, it may not provide evidence of what actually occurs in the second language classroom. Therefore, more research needs to be done on the interaction modifications inside the language classroom. With special care taken to ensure the quality of the recorded interactions, this would allow researchers to examine how learners normally behave.

\section{Implications for Teacining}

The results of this case study suggest that culture does play a role in how learners negotiate for meaning with their interlocutors. ESL/EFL teachers need to be aware of these influences so that they can choose culturally appropriate methods of instruction. In the case of Japanese students, this study found that they use interaction modifications much more frequently in small group or pair work situations. Instructors can utilize these findings to encourage increased language proficiency by moving away from teacher-fronted classes as much as possible. As noted previously, opportunities to negotiate meaning or exchange information are limited in 
teacher fronted classes since information flows in only one direction; from the teacher to the students. Often, the students only chance for production comes when supplying answers to questions asked by the teacher. In many lessons, either teacher-fronted or small group work, learners often must comply with goals they have had no part in setting. Thus, their opportunities to work toward collective or individual goals are blocked, as the teacher controls both the questions that are asked and the responses that are expected. Opportunities to negotiate meaning or exchange information are also limited since the learners have little interest in or control over the objectives. Learners may be reluctant to signal lack of understanding, either because the topic of the discourse has little consequence for the learner or because any indication of a lack of understanding would suggest their lack of competence or loss of attention. Therefore, learners need to be included in decision making, and allowed to select tasks or topics that are of interest to them.

Although explicit instruction is essential at times in any ESL/EFL setting, the style of instruction can be modified in order to encourage student use of interaction modifications. In teacher-fronted classes, instructors need to be aware of the amount of interaction modifications they use, and encourage their students to utilize interaction modifications as well. Instead of solving communication problems for the learners, either by guessing what they mean or supplying missing structures, teachers can 
utilize clarification requests to encourage learners to correct communication problems themselves. Also, instructors can encourage student use of interaction modifications by limiting the number of comprehension checks they employ. These comprehension checks generally elicit a choral response of "yes" from the learners. Instead, instructors can use confirmation checks and clarification requests to involve the learners more directly in the lesson and discussion.

Culture should not be viewed as an obstacle to gaining language proficiency that must be overcome, but as an asset in understanding student behavior. Japanese learners need to be assured that the use of interaction modifications is appropriate in the ESL/EFL classroom. Since the Japanese subjects in this study did use some interaction modifications, this encouragement may be all that is necessary to allow Japanese students to feel more comfortable in adjusting their communication strategies. By explaining the use of interaction modifications, and supplying learners with some formulaic expressions that they can build on, ESL/EFL instructors can promote their use and give their students another tool to increase proficiency in the target language.

\section{Conclusion}

This case study has examined the interaction modifications used by Japanese ESL students and their possible effect on language proficiency, as measured by increase in test scores, in a content based ESL classroom. 
Observing these student-student, and student-teacher interactions can aid in the understanding of second language acquisition.

As reported in the study, learner use of interaction modifications is correlated with increases in CELT test scores. Also, use of confirmation checks and responses to clarification requests by the learners produced longer, more syntactically complex phrases than other interaction modifications.

Since interaction modifications allow students to negotiate meaning in order to obtain comprehensible input, and produce output based on their IL rules, their use, particularly in the ESL/EFL classroom, should be encouraged. 


\section{References}

Allen, P., Frohlich, M., \& Spada, N. (1984). The communicative orientation of language teaching: An observation scheme. In J. Handsecombe, R. Orem, and B. Taylor (Eds.), On TESOL '83: The Question of Control, 231-152. TESOL.

Aston, G. (1986). Trouble-shooting in interaction with learners: The more the merrier? Applied Linguistics, $7,128-143$.

Barnlund, D. (1975). Public and Private Self in Japan and the United States: Communicative Styles of Two Cultures. Tokyo: Simil Press.

Beauchamp, E. (1992). Japanese and U.S. Education Compared. Bloomington, Ind.: Phi Delta Kappa Educational Foundation.

Brown, P \& Levinson, S. (1987). Politeness: Some Universals in Language Usage. Cambridge: Cambridge University Press.

Chaudron, C. (1985). Intake: On models and methods for discovering learners' processing of input. Studies in Second Language Acquisition, 7, 1-14.

Derwing, T. (1989). Information type and its relation to nonnative speaker comprehension. Language Learning, 39, 157-72.

Doughty, C. (1991). Second language instruction does make a difference: Evidence from an empirical study of SL relativization. Studies in Second Language Acquisition, 13, 431-470.

Doughty, C. \& Pica, T. (1986). "Information gap" tasks: Do they facilitate second language acquisition? TESOL Quarterly, 20, 305-25.

Ehrlich, S., Avery, P., \& Yorio, C. (1989). Discourse structure and the negotiation of comprehensible input. Studies in Second Lanquage Acquisition, 11, 397-414.

Ellis, R. (1991). The interaction hypothesis: A critical evaluation. (ERIC reproduction document no. ED 338 037)

Ellis, R., Tanaka, Y. \& Yamazaki, A. (1994). Classroom interaction, comprehension, and the acquisition of $L 2$ word meanings. Lanquage Learning, 44 (3), 449-491. 
Faerch, C. \& Kasper, G. (1986). Cognitive dimensions of language transfer. In E. Kellerman and M. Sharwood Smith (Eds.), Cross-Linguistic Influence in Second Language Acquisition. Oxford: Pergamon.

Gass, S. \& Varonis, E. (1985). Task variation and nonnative/nonnative negotiation of meaning. In S. Gass and C. Madden (Eds.), Input in Second Lanquage Acquisition. Rowley, MA: Newbury House.

Hall, E. (1976). Beyond culture. New York: Doubleday.

Hall, E. (1984). The dance of life: The other dimension of time. Garden City, N.Y.: Anchor Press.

Hatch, E. (1978). Discourse analysis and second language acquisition. In E. Hatch (Ed.), Second Language Acquisition: A Book of Readings, 401435. Rowley, MA: Newbury House.

Hawkins, B. (1985). Is the appropriate response always so appropriate? In S. Gass and C. Madden (Eds.), Input in Second Language Acquisition. Rowley, MA: Newbury House.

Honna, N. \& Hoffer, B. (Eds.) (1989). An English Dictionary of Japanese Ways of Thinking. Tokyo: Yuhikaku.

Ishii, S. \& Bruneau, T. (1994). Silence and silences in cross-cultural perspective: Japan and the United States. In R.E. Porter and L.A. Samovar (Eds.), Intercultural Communication: A Reader, 7th ed., 246251. Wadsworth Publishing Company.

Ishii, S., Klopf, D.W., \& Cambra, R.E. (1984). The typical Japanese student as an oral communicator: A preliminary profile. Otsuma Review, 17, 3963.

Jorden, E. (1992). Culture in the Japanese language classroom: A pedagogical paradox. In C. Kamsch, and S. McConnell-Ginet (Eds.), Text and Context: Cross-Disciplinary Perspectives on Language Study, 156-167. Lexington, Mass.: D.C. Heath and Company.

Kitazawa, M. (1990). Is Pica and Doughty's system of interaction classification applicable to a Japanese language classroom? Unpublished D.Ed. paper, Temple University, Tokyo, Japan. 
Krashen, S. (1977). Some issues relating to the monitor model. In $\mathrm{H}$. Brown, C. Yorio and R. Crymes, (Eds. ), On TESOL '77, 144-158. Washington, D.C.: TESOL.

Krashen, S. (1980). The input hypothesis. In J. Alatis (Ed.), Current Issues in Bilingual Education, 144-158. Washington, DC: Georgetown University Press.

Krashen S. (1983). Newmark's "Ignorance Hypothesis" and current second language acquisition theory. In S. Gass \& L. Selinker (Eds.), Language Transfer in Lanquage Learning, 135-153. Rowley, MA: Newbury House.

Krashen, S. (1985). The Input Hypothesis: Issues and Implications. London: Longman.

Krashen, S. (1989). We acquire vocabulary and spelling by reading: Additional evidence for the input hypothesis. Modern Language Journal, $\underline{73}, 440-64$.

Kurogi, Atsuko (1990). Communication Stress and Coping Strategies Among Japanese University Students in the U.S. Unpublished master thesis, Portland State University, Portland, Oregon.

Larsen-Freeman, D. \& Long, M. (1991). An Introduction to Second Lanquage Acquisition Research. London: Longman.

Lebra, T.S. (1976). Japanese Patterns of Behavior. Honolulu: University of Hawaii Press.

Lennnon, P. (1989). Introspection and intentionality in advanced secondlanguage acquisition. Language Learning, 39, 375-95.

Long, M. (1980). Input, Interaction, and Second Lanquage Acquisition. Unpublished doctoral dissertation, University of California, Los Angeles.

Long, M. (1981). Questions in foreigner talk discourse. Language Learning, 31, 135-157.

Long, M. (1983a). Linguistic and conversational adjustments to non-native speakers. Studies in Second Language Acquisition, $\underline{5}$, 177-183.

Long, M. (1983b) Native speaker/non-native speaker conversation in the second language classroom. On TESOL '82: Pacific Perspectives on Language and Teaching. TESOL. 
Long, M. (1985). Input and second language acquisition theory. In S. Gass \& C. Madden (Eds.), Input in Second Language Acquisition, 377-393. Rowley, MA: Newbury House.

Long, M. (1989). Task, group and task-group interactions. University of Hawaii Working Papers in ESL, $\underline{8}, 1-26$.

Long, M \& Sato, C. (1983). Classroom foreigner talk discourse: Forms and functions of teachers' questions. In H.W. Seliger \& M.H. Long (Eds.), Classroom Oriented Research in Second Lanquage Acquisition, 268285. Rowley, MA: Newbury House.

Loschky, L. (1988). The Effects of Task and Culture on Negotiated Interaction, Paper presented at the Eighth Second Language Research Forum, University of Hawaii at Manoa, Honolulu.

Loschky, L. (1989). The Effects of Negotiated Interaction and Premodified Input on Second Language Comprehension and Retention. (Occasional Paper No. 16) Honolulu: University of Hawaii at Manoa, Department of English as a Second Language.

Loschky, L. (1994). Comprehensible input and second language acquisition: What is the relationship? SSLA, 16, 303-323.

Nakane, C. (1977). Japanese Society. Berkley, CA: University of California Press.

Okabe, K. (1987). Indirect speech acts of the Japanese. In D. Lawrence Kincaid (Ed.), Communication Theory: Eastern and Western Perspectives, 127-136. San Diego: Academic Press, Inc.

Parker, K. \& Chaudron, C. (1987). The effects of linguistic simplifications and elaborative modifications on L2 comprehension. University of Hawaii Working Papers in ESL, $\underline{6}, 107-133$.

Pica, T. (1989). Classroom interaction, participation and comprehension: Redefining relationships. Papers in Applied Linguistics, University of Alabama, 1, 1-36.

Pica, T. (1992). The textual outcomes of native speaker-non-native speaker negotiation: What do they reveal about second language learning. In $\mathrm{C}$. Kramsch \& S. McConnell-Ginet (Eds.), Text and Context: CrossDisiplinary Perspectives on Language Study, Lexington, MA: D.C. Heath and Company. 
Pica, T., Lincoln-Porter, F., Paninos, D., Linnell, J. (1995).What can second language learners learn from each other?: Only their researcher knows for sure. University of Pennsylvania Working Papers in Educational Linguistics, 11 (1), 1-36.

Pica, T. \& Doughty, C. (1985). Input and interaction in the communicative language classroom: A comparison of teacher fronted and group activities. In S. Gass \& C. Madden (Eds.), Input in Second Language Acquisition, 377-393. Rowley, MA: Newbury House.

Pica, T., Holliday, L., Lewis, N., \& Morgenthaler, L. (1989). Comprehensible output as an outcome of linguistic demands on the learner. Studies in Second Lanquage Acquisition, 11, 63-90.

Pica, T. \& Long, M. (1986). The linguistic and conversational performance of experienced and inexperienced teachers. In R. Day (Ed.), Talking to Learn: Conversation in Second Language Acquisition, 85-98. Rowley, MA: Newbury House.

Pica, T., Young, R., \& Doughty, C. (1987). The impact of interaction on comprehension. TESOL Quarterly, 21, 737-758.

Pienemann, M. (1989). Is language teachable? Psycholinguistic experiments and hypotheses. Applied Linquistics, 10, 52-79.

Ramsey, S. (1985). To hear one and understand ten: Nonverbal behavior in Japan. In R.E. Porter and L.A. Samovar (Eds.), Intercultural Communication: A Reader, 7th ed., 246-251. Wadsworth Publishing Company.

Reischauer, Edwin O. (1977). The Japanese. The Belknap Press of Harvard University Press.

Sachs, J., Bard, B., \& Johnson, M. (1981). Language learning with restricted . input: Case studies of two hearing children of deaf parents. Applied Psycholinguistics, 2, 33-54.

Sato, C. (1981). Ethnic styles in classroom discourse. In M. Hines \& W. Rutherford (Eds.), On TESOL '81, 11-24. Washington D.C.: TESOL.

Schmidt, R. (1990). The role of consciousness in second language leaming. Applied Linguistics, 11, 129-58. 
Schmidt, R. \& Frota, S. (1986). Developing basic conversational ability in a second language: A case-study of an adult learner. In R. Day (Ed.), Talking to Learn: Conversation in Second Language Acquisition. Rowley, MA: Newbury House.

Sharwood Smith, M. (1986). Comprehension vs. acquisition: Two ways of processing input. Applied Linguistics, 7 , 239-56.

Spada, N. (1987). Relationships between instructional differences and learning outcomes: A process-product study of communicative language teaching. Applied Linguistics, $\underline{8}, 137-61$.

Spada, N. \& Frohlich, M. (1995). Communicative Orientation of Language Teaching Observation Scheme: Coding Conventions and Applications. Sydney: Macquarie University, National Centre for English Language Teaching and Research.

Spada, N. \& Lightbown, P. (1989). Intensive ESL programmes in Quebec primary schools. TESL Canada, $\underline{7}, 11-32$.

Swain, M. (1985). Communicative competence: Some roles of comprehensible input and comprehensible output in its development. In S. Gass \& C. Madden (Eds.), Input in Second Lanquage Acquisition, 235-253. Rowley, MA: Newbury House.

Snow, C., Arlman-Rupp, A., Hassing, Y., Jobse, J., Joosten, J., \& Yorster, J. (1976). Mothers' speech in three social classes. Journal of Psycholinguistic Research, $\underline{5}, 1-20$.

Taylor, J. (1983). Shadows of the Rising Sun. NY: Harcourt Brace Jovanovich.

Tsujimura, A. (1987). Some characteristics of the Japanese way of communication. In D. Lawrence Kincaid (Ed.), Communication Theory: Eastern and Western Perspectives, 115-126. San Diego: Academic Press, Inc.

Watanabe, S. (1990). Framing in American and Japanese Group Discussions. Unpublished doctoral dissertation, Georgetown University, Washington D.C.

Wells, G. (1985). Language Development in the Pre-School Years. Cambridge: Cambridge University Press. 
White, L. (1987). Against comprehensible input: The input hypothesis and the development of second language competence. Applied Linguistics, 8, 95-110.

Wierzbick, A. (1991). Japanese key words and core cultural values.

Lanquage in Society, 20 (3), 333-385. 
SJOIONJdd 
APPENDIX A

SUBJECTS' TEST SCORES

\begin{tabular}{lcccc}
\hline Subject & $\begin{array}{c}\text { Michigan } \\
\text { Test } \\
\text { (March) }\end{array}$ & $\begin{array}{c}\text { Michigan } \\
\text { Test } \\
\text { (August) }\end{array}$ & $\begin{array}{c}\text { CELT } \\
\text { (June) }\end{array}$ & $\begin{array}{c}\text { CELT } \\
\text { (August) }\end{array}$ \\
\hline S1 & 21 & 25 & 23 & 24 \\
S2 & 27 & 43 & 30 & 26 \\
S3 & 31 & 23 & 27 & 26 \\
S4 & 28 & 29 & 27 & 29 \\
S5 & 35 & 47 & 30 & 36 \\
S6 & 32 & 38 & 29 & 34 \\
S7 & 33 & 37 & 34 & 35 \\
S8 & 30 & 39 & 34 & 33 \\
S9 & 39 & 29 & 28 & 30 \\
S10 & 27 & 40 & 27 & 27 \\
S11 & 40 & 36 & 24 & 24 \\
S12 & 34 & 41 & 26 & 26 \\
\hline
\end{tabular}




\section{APPENDIX B}

\section{CELT}

CELT: Comprehensive English Language Test (copyright 1970)

A Comprehensive English Language Test for Speakers of English as a Second Language.

Listening: test of the subjects' ability to comprehend spoken English.

In three parts:

(1) Answering questions (20 questions)

The subjects read four possible answers and must decided which is the best answer to the question they have heard.

Example:

"When are you going to New York"
(A) To visit my brother.
(B) By plane.
(C) Next Friday.
(D) Yes, I am.

(2) Understanding statements (20 questions)

After the subjects hear the statement, they must read four sentences and decide which one is the closest in meaning to the statement they heard.

Example:

"George has just returned home from his vacation."
(A) George is spending his vacation at home.
(B) George has just finished his vacation.
(C) George is just about to begin his vacation.
(D) George has decided not to take a vacation.

(3) Comprehending dialogues (10 questions)

The subjects listen to a dialogue between a man and a women. At the end of each conversation a third voice asks a question about it. The subjects read four possible answers 
and decide which one is the best answer to the question asked.

Example:

"Are you still planning to leave for New York next Monday?"

"I'm afraid not. My husband just found out he'll be in a meeting until late that afternoon, so we won't be able to get started until the following morning."

On what day does the woman expect to leave for New York?
(A) Sunday
(B) Monday
(C) Tuesday
(D) Wednesday 


\section{APPENDIX C}

\section{SAMPLE CORPUS AND CODING}

9:30 UNIX Practice T->Ss Oral, H.O., O.H.

T: Please go to the shell prompt here.

You need to exit the main menu and go to the shell prompt. ...

Ss: (In Japanese, on task)

$\mathrm{T}$ : OK, could you get the paper I gave you called "Unix practice". ... Would you read number one, (S7)?

S7: ......

T: Ok, we did this the other day, but you can go ahead....

S6: Pico?

L2/mess.-Clar. req./unrestr./ultramin.

S12: P-I-C-O L2/unpred. info./unrestr./min.

S6: When we want to make file? L2/mess.-Conf. check/unrestr./min.

S12: Yes. Type Pico. L2/mess.-com.//L2/unpred. info./unrestr./min.

$\mathrm{T}$ : (helping students) ...

S12: (incomprehensible)

S6: Control ... X. L2/mess.-Conf. check/unrestr./min.

S12: (laughs) Yes. L2/mess.-com./unrest./ultramin.

$\mathrm{T}$ : Then, if you want to check if you 
have the file there, type Is to list it. And then you can see, I have a file here called "apples". ...

Ss: (in Japanese, on task)

T: So you should have three files, apples, bananas, peaches.

S6: Three file?

L2/mess.-Confirm.

check/unrest./min.

T: Three files, one called .... L2/unpred.-info./min.

S6: Three files? (in Japanese, "What's that?")

L2/mess.-Clarif. req.//L1/unrest./min.

S12: Make three file. Name is apples, L2/unpred.-info./unrest/min. bananas, peaches

S6: Huh?

L2/mess.-Clarif. req./unrest./ultramin.

S12: (points to her screen) Like this. L2/unpred.-info./unrest./min.

Then control $X$.

S6: Control $x$ ? Why control X?

L2/mess.-rep.//L2/mess.-Clarif. req./unrest/min.

S12: To exit to see your file. L2/unpred. info./unrest./min.

S6: I don't see it (a file). Why? L2/unpred.-info//L2/gen. req./unrest./min.

S12: I don't know. (they both laugh) L2/upred. info.//L2/unpred. Type Pico space file name (repetition info./unrest/min. of T's instructions).

S6: Ok.

L2/mess. com./unrest/ultramin. 